\title{
INFORMATION-BASED DESIGN OF POLYMERIC DRUG FORMULATION ADDITIVES
}

SANDRA ARIAS, EVA MARON, HANS G. BÖRNER

Prof. Hans G. Börner

Humboldt-Universität zu Berlin, Brook-Taylor-Str. 2, 12489 Berlin, Germany

E-Mail: h.boerner@hu-berlin.de

Phone: +49 (0)30-2093 7348

Fax: $+49(0) 302093-7500$ 
2 Instrumentation and general analysis procedures.......................................................

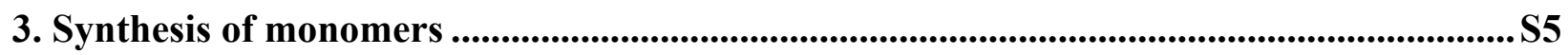

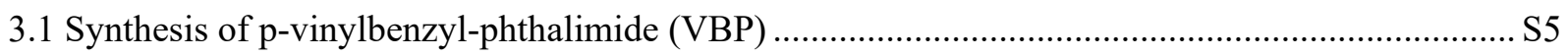

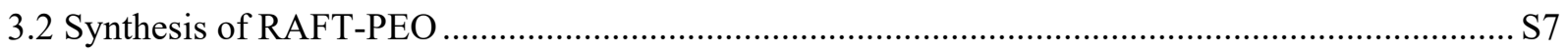

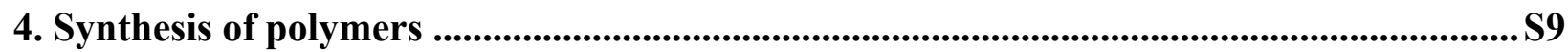

4.1 Synthesis of $\alpha$-mPEG- $\omega$-RAFT-Poly(Styrene)-alt-Poly(Maleic anhydride): P[S-alt-MA $]_{\mathrm{n}}-\mathrm{PEG} \ldots$... S9

4.2 Synthesis of $\alpha$ - mPEG - $\omega$ - RAFT - Poly (p-vinylbenzylphthalimide)-alt-Poly(Maleic anhydride):P[VBP-alt-MA $]_{2}$-PEG

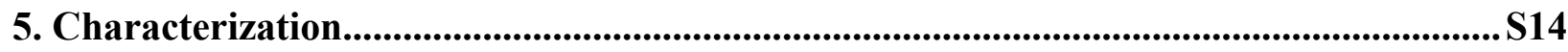

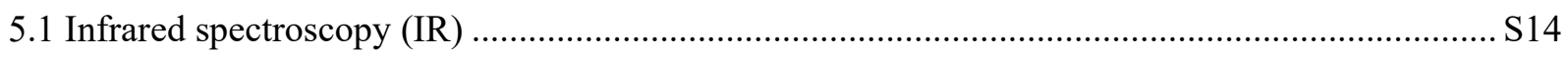

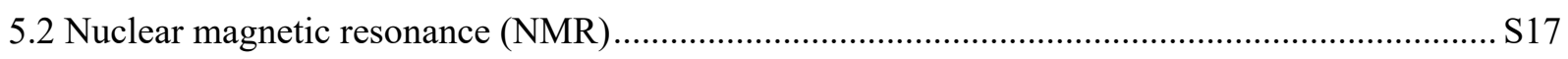

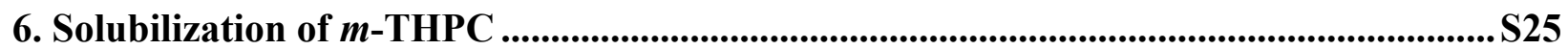

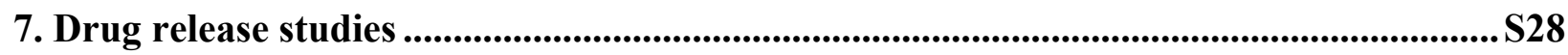




\section{Materials}

Monomers \& monomer synthesis: 4-Cyano-4-(phenylcarbonothioylthio)pentanoic acid used as chain transfer agent (CTA, Sigma-Aldrich), 4-dimethylaminopyridine (DMAP, Fluka, $\geq 98.0 \%$ (NT)) and N,N'-dicyclohexylcarbodiimide (DCC, Iris Biotech GmbH) and mPEG5000 (SigmaAldrich). Phthalimide potassium salt (Sigma-Aldrich, 98\%), 4-vinylbenzyl chloride (SigmaAldrich, 90\%), maleic anhydride (MA, Sigma-Aldrich, 99\%), isopropyl amine (Sigma-Aldrich, $\geq 99.5 \%$ ), isobutyl amine (Sigma-Aldrich, 99\%). Dichloromethane (DCM) was dried by calcium hydride (Sigma-Aldrich, reagent grade, 95\%) and dry dimethylformamide (DMF, Sigma-Aldrich, 99\%) was used as received.

Polymer synthesis: 1,1'-azobis(isobutyronitrile) (AIBN, Sigma-Aldrich, 98\%) was recrystallized twice from methanol prior to use. 1,4-Dioxane (Sigma Aldrich, 99\%), Styrene (Sigma-Aldrich, ReagentPlus $\left.{ }^{\circledR}, 99.9 \%\right)$ was filtered over $\mathrm{Al}_{2} \mathrm{O}_{3}$ to remove stabilizers and chloroform $\left(\mathrm{CHCl}_{3}\right.$, VWR, $\geq 99.5 \%$ for HPLC) was used as received.

\section{Instrumentation and sample analysis procedures}

Nuclear magnetic resonance spectroscopy (NMR): ${ }^{1} \mathrm{H}(400,500 \mathrm{MHz})$ and ${ }^{13} \mathrm{C}$ NMR $(100$, $125 \mathrm{MHz}$ ) spectra in $\mathrm{CDCl}_{3}$ or DCM-d2 were acquired from Bruker spectrometers and calibrated to residual solvent peaks ( $\delta 7.26$ and $\delta 77.13$ for $\mathrm{CDCl}_{3}$ and $\delta 5.32$ for DCM-d2). NMR spectra were analyzed via MestReNova software. All chemical shifts are recorded in ppm $(\delta)$ and determined relative to the residual solvent absorption peaks. The multiplicities were explained using the following abbreviations: $\mathrm{s}$ for singlet, $\mathrm{d}$ for doublet, $\mathrm{t}$ for triplet, $\mathrm{m}$ for multiplet, $\mathrm{bs}$ for broad signal and dd for doublet of doublets.

Gel permeation chromatography (GPC) .GPC measurements were conducted using WGE Dr. Bures-Systems (WGE Dr. Bures GmbH \& Co. KG, Dallgow Doeberitz, Deutschland) and with the application of refraction index detectors (Knauer RI K-2301). Tetrahydrofuran (THF) was used 
as eluent and PSS columns (50 - $1000 \AA$ ) were used for size exclusion. Polystyrene standards with low dispersity were used for calibration. 2,4-di-tert-butyl-4-methoxy-phenol was used as an internal standard. The measurement was conducted at $60{ }^{\circ} \mathrm{C}$ with a flow rate of $1 \mathrm{ml} / \mathrm{min}$.

Fourier transformation infrared spectroscopy (FT-IR). FT-IR spectra were recorded on a Bruker Vertex 70v FT-IR spectrometer (Bruker Optics GmbH, Ettlingen, Germany) with an evacuable optics bench in a range from $4000-400 \mathrm{~cm}^{-1}$. Samples were measured in solid form in ATR-IR modus under vacuum system.

Ultraviolet-visible spectroscopy (UV-Vis). UV-Vis spectroscopy was performed using a Shimadzu UV-2501 PC spectrometer (Shimadzu Corp., 604-8511 Kyoto, Japan) using PS-cuvettes with $10 \mathrm{~mm}$ path.

Fluorescence. Steady-state fluorescence emission spectra and kinetics were recorded on a Synergy MXmicroplate reader (BioTek, Winooski, VT 05404, USA) in black polystyrene 96-well plates.

Dynamic Light Scattering (DLS) data were collected on a Malvern Zetasizer nano-ZS (Malvern Instruments Ltd., Worcestershire, UK) equipped with a He-Ne-Laser $(\lambda=632.8 \mathrm{~nm})$ on $400 \mu \mathrm{L}$, aliquots of polymer-solutions with and without $m$-THPC incubation. DLS experiments were repeated three times. Hydrodynamic radii RH were calculated using Stokes-Einstein equation (eq $1)$.

$$
R_{H}=\frac{k T}{6 \pi \eta \mu} \quad(\text { eq } 1)
$$

with $\mathrm{k}=1.38 \times 10-23, \mathrm{~T}=293 \mathrm{~K}, \eta=$ Viscosity, $\mu=$ Diffusion coefficient. 


\section{Synthesis of monomers}

\subsection{Synthesis of p-vinyl benzyl-phthalimide (VBP)}

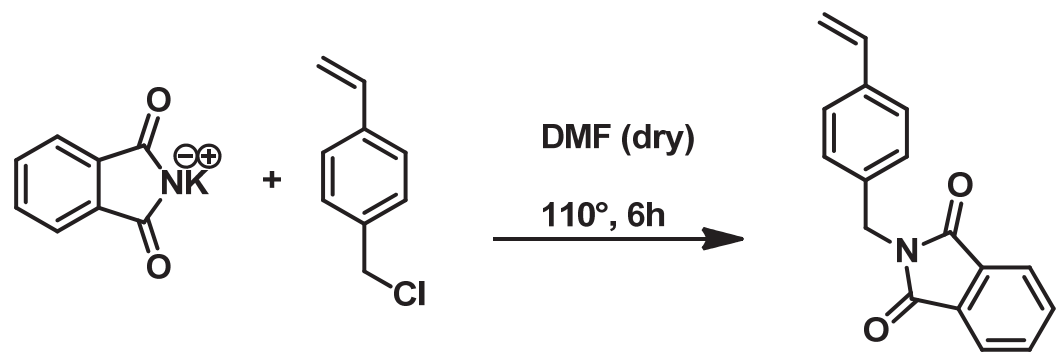

$20.4 \mathrm{~g}$ Potassium phthalimide $(110.2 \mathrm{mmol})$ and $12 \mathrm{~mL}$ 4-Vinylbenzyl chloride (85.2 mmol) was dissolved in $100 \mathrm{~mL}$ DMF. The suspension was heated and stirred at $110^{\circ} \mathrm{C}$ for $5 \mathrm{~h}$. After cooling, $400 \mathrm{~mL}$ water and $200 \mathrm{~mL}$ ethyl acetate were added. The aqueous phase was extracted three times with $200 \mathrm{~mL}$ ethyl acetate. The united organic phases were washed, dried over $\mathrm{MgSO}_{4}$ and evaporated. The beige residue was dissolved in $50 \mathrm{~mL}$ chloroform at $40{ }^{\circ} \mathrm{C}$. The solution was added to $500 \mathrm{~mL}$ ice cooled pentane, giving sediment. The crude product was filtered and washed with cold pentane. The beige residue was dried in high vacuum, giving $18.1 \mathrm{~g} p$-vinyl benzyl phthalimide (68.0 mmol, 81\%).

${ }^{1} \mathrm{H} \mathrm{NMR}\left(300 \mathrm{MHz}^{\left.-\mathrm{CDCl}_{3}\right)} \delta[\mathrm{ppm}] 7.68(\mathrm{dd}, J=5.5,3.1 \mathrm{~Hz}, 2 \mathrm{H}), 7.53(\mathrm{dd}, J=5.5\right.$, $3.0 \mathrm{~Hz}, 2 \mathrm{H}), 7.27(\mathrm{~d}, J=8.3 \mathrm{~Hz}, 2 \mathrm{H}), 7.23-7.20(\mathrm{~m}, 2 \mathrm{H}), 6.53(\mathrm{dd}, J=17.6,10.9$ $\mathrm{Hz}, 1 \mathrm{H}), 5.58(\mathrm{dd}, J=17.6,0.7 \mathrm{~Hz}, 1 \mathrm{H}), 5.09(\mathrm{dd}, J=10.9,0.7 \mathrm{~Hz}, 1 \mathrm{H}), 4.69(\mathrm{~s}$, $2 \mathrm{H})$.

${ }^{13} \mathrm{C} \mathrm{NMR}\left(126 \mathrm{MHz}, \mathrm{CDCl}_{3}\right) \delta 168.02,137.17,136.32,135.90,134.01,132.07$, $128.86,126.50,123.45,123.33,114.17,41.32$. 


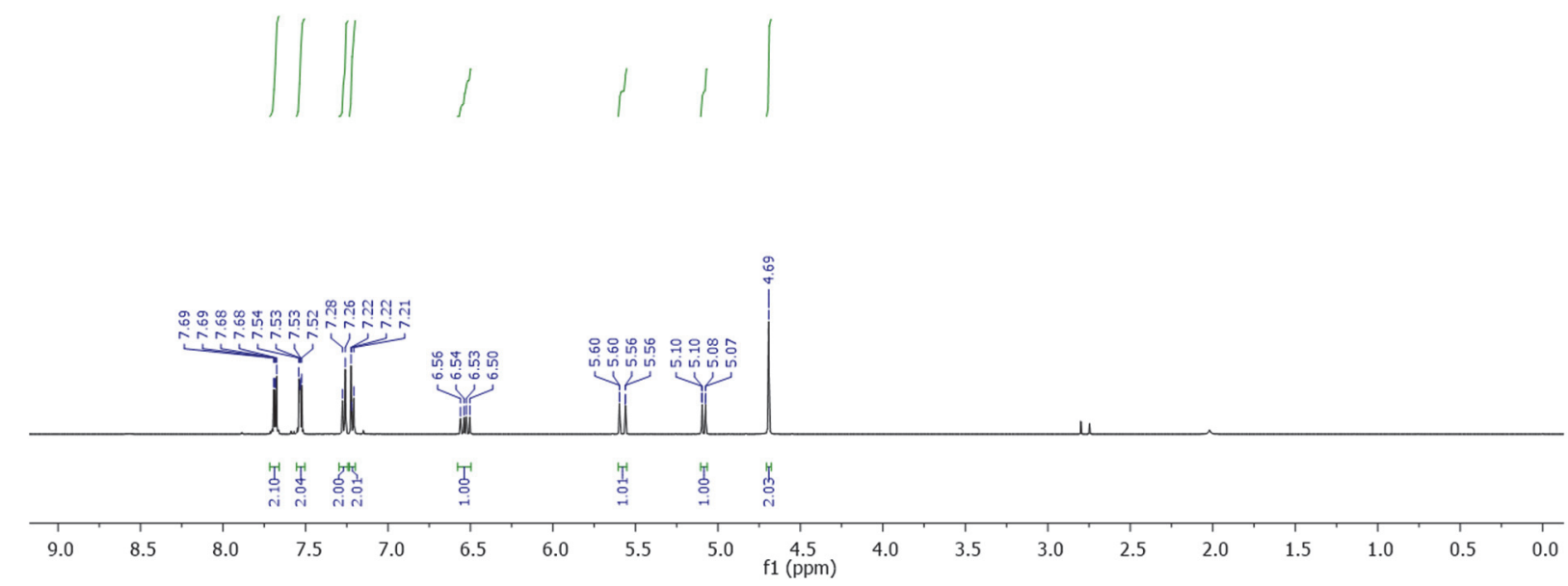

Figure S1. ${ }^{1} \mathrm{H}$ NMR of $p$-vinyl benzyl phthalimide.

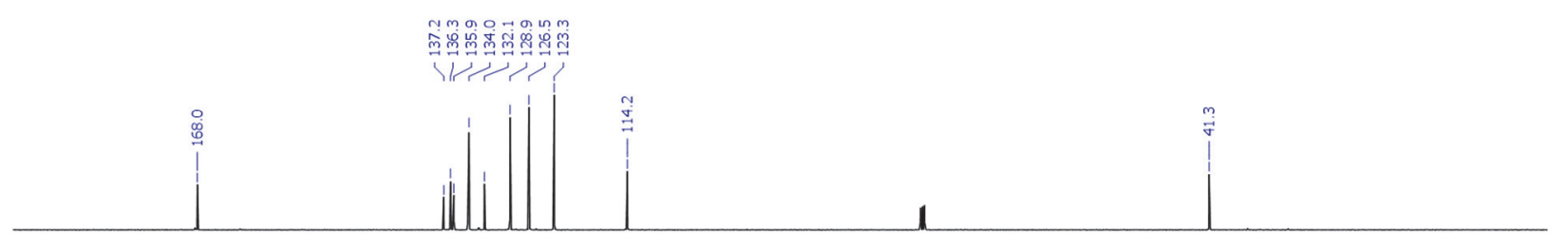

\begin{tabular}{|c|c|c|c|c|c|c|c|c|c|c|c|c|c|c|c|c|}
\hline 190 & 180 & 170 & 160 & 150 & 140 & 130 & 120 & 110 & ${ }_{\mathrm{f} 1(\mathrm{ppm})^{90}}^{90}$ & 80 & 70 & 60 & 50 & 40 & 30 & 10 \\
\hline
\end{tabular}

Figure S2. ${ }^{13} \mathrm{C}$ NMR of $p$-vinyl benzyl phthalimide. 
<smiles>CC(C)(C)OCC(C)(C)OC(=O)CCC(C)(C)SC(=S)c1ccccc1</smiles>

$1.0 \mathrm{~g}$ (3.57 mmol) of PEG 4-cyan-4(phenylcarbonothioylthio)pentanoic acid and $0.08 \mathrm{~g}(0.71$ mmol) of DMAP were added to a solution of PEG $(5000 \mathrm{~g} / \mathrm{mol}) 1.79 \mathrm{~g}(0.35 \mathrm{mmol})$ in $20 \mathrm{~mL}$ of dry DCM. The reaction flask was cooled in an ice bath and the solution were stirred for $10 \mathrm{~min}$, followed by dropwise addition of $0.738 \mathrm{~g}(3.58 \mathrm{mmol})$ of DCC in $5 \mathrm{~mL}$ of dry DCM. The reaction mixture was stirring for $24 \mathrm{~h}$ at room temperature. The raw product was filtered and dried. Afterwards, the raw product was purified by precipitating it in cold diethyl ether and dissolved in dichloromethane (3x).1.15 g $82 \%$ yield (97\% conversion).

${ }^{1} \mathrm{H} \mathrm{NMR}\left(300 \mathrm{MHz}, \mathrm{CDCl}_{3}\right) \delta[\mathrm{ppm}]: 7.91(\mathrm{~s}, 2 \mathrm{H}), 7.58(\mathrm{~s}, 1 \mathrm{H}), 7.38(\mathrm{~s}, 2 \mathrm{H}), 4.27(\mathrm{~d}$, $\mathrm{J}=13.4 \mathrm{~Hz}, 2 \mathrm{H}), 3.87(\mathrm{dd}, \mathrm{J}=5.6,4.2 \mathrm{~Hz}, 3 \mathrm{H}), 3.63(\mathrm{~s}, 472 \mathrm{H}), 3.40(\mathrm{dd}, \mathrm{J}=5.6,4.2$ $\mathrm{Hz}, 3 \mathrm{H}), 3.37(\mathrm{~s}, 3 \mathrm{H}), 2.70(\mathrm{~s}, 3 \mathrm{H}), 2.43(\mathrm{~s}, 1 \mathrm{H}), 1.93(\mathrm{~s}, 3 \mathrm{H})$. 


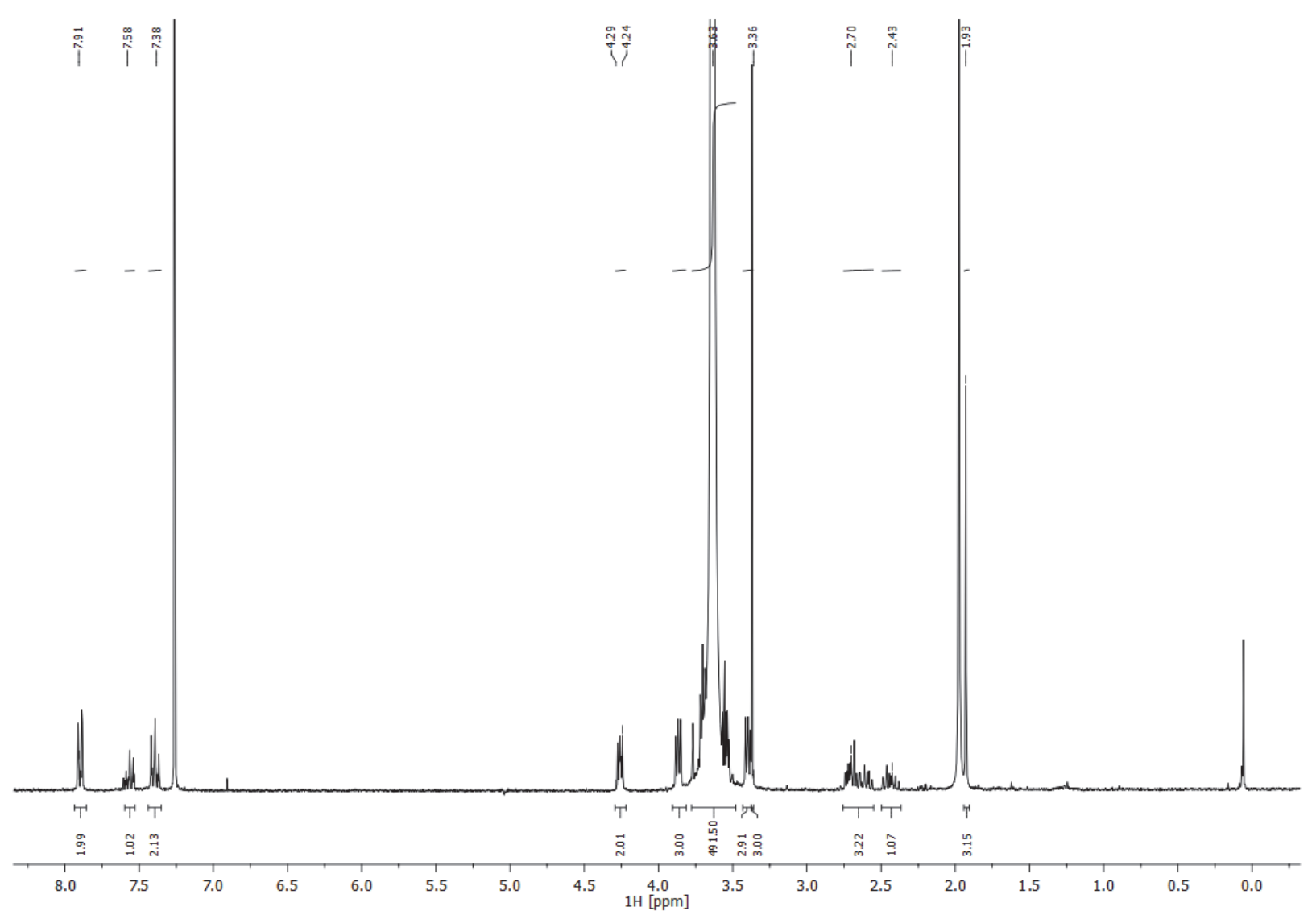

Figure S3. ${ }^{1} \mathrm{H}$ NMR of $m$ PEG-CTA.

\begin{tabular}{c|c|c} 
Polymer & Mn & Ð \\
\hline PEG & 5000 & 1.09 \\
\hline$m$ PEG-CTA & 5200 & 1.04
\end{tabular}

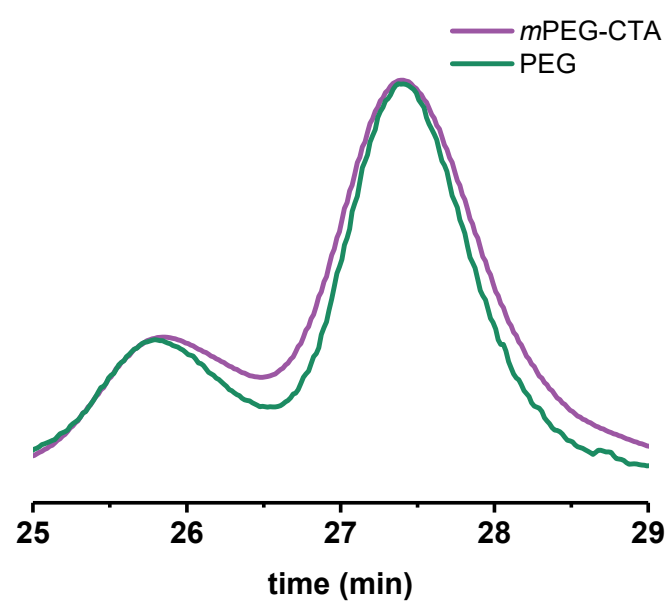

Figure S4. GPC data for the series of PEG and RAFT-PEG 


\section{Synthesis of polymers}

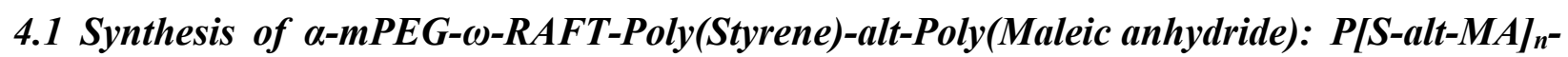
$P E G$<smiles>CC(C)OCC(=O)CCC(C)(C)SC(=S)c1ccccc1</smiles>

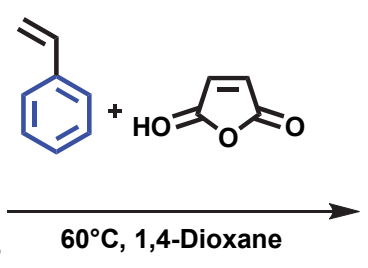

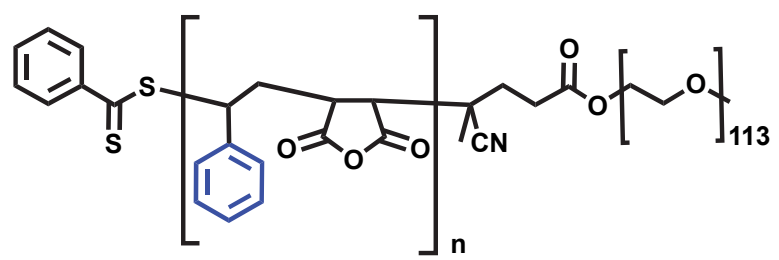

P[S-alt-MA $]_{n}$-PEG $\mathrm{n}=2,4,6$

$0.447 \mathrm{~g}$ (4.56 mmol, 20 equiv.) maleic anhydride, $0.474 \mathrm{~g}$ (4.56 mmol, 20 equiv.) styrene, 0.0037 g (0.0228 mmol, 0.1 equiv.) AIBN and $1.2 \mathrm{~g}$ (0.228 mmol, 1 equiv.) RAFT-PEO (5000 g/mol) was dissolved in $14 \mathrm{~mL}$ 1,4-dioxane. After freeze-pump-thaw degassing of the reaction mixture (3x) the reaction mixture was heated at $60^{\circ} \mathrm{C}$ for $15 \mathrm{~h}\left(\mathrm{P}[\mathrm{S}-\text { alt-RMA }]_{2}-\mathrm{PEG} 18 \%\right.$ conversion), 24 h (P[S-alt-MA]4-PEG 28\% conversion) and 35 h (P[S-alt-RMA $]_{6}-\mathrm{PEG} 39 \%$ conversion). Considering the uncertain fractionation occurring during polymer precipitation, the DP of the functional segments was determined by NMR on the stage of the final products. The different polymers were purified by precipitating it in cold diethyl ether and dissolved in dichloromethane $(3 x)$

\begin{tabular}{c|c|c|c} 
Polymer & Mn & Ð & DP* \\
\hline $\mathrm{P}[\mathrm{S}-$ alt-MA]2-PEG & 5800 & 1.02 & 2 \\
\hline $\mathrm{P}[\mathrm{S}-\text { alt }-\mathrm{MA}]_{4}-\mathrm{PEG}$ & 6100 & 1.02 & 4 \\
\hline $\mathrm{P}[\mathrm{S}-\text { alt }-\mathrm{MA}]_{6}-\mathrm{PEG}$ & 6550 & 1.08 & 6
\end{tabular}

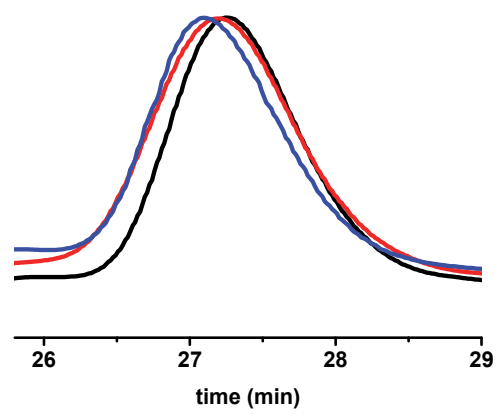

Figure S5. GPC data for the series of P[S-alt-MA $]_{\mathrm{n}}-\mathrm{PEG}(*$ functional block). 


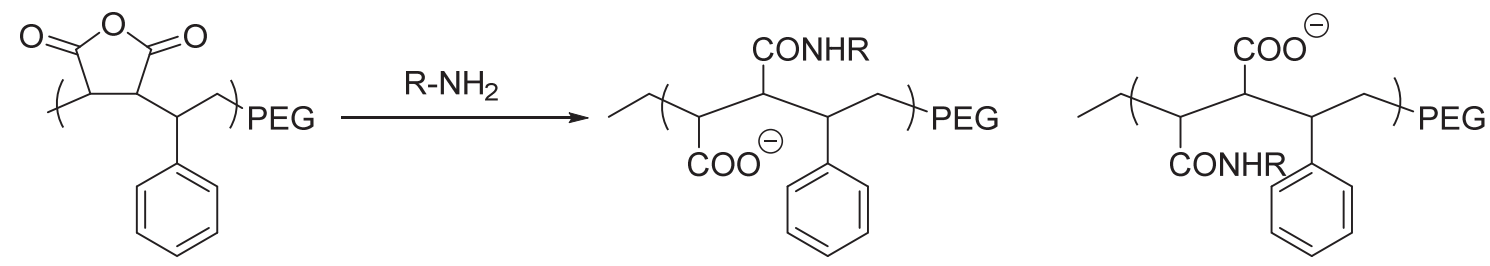

Scheme S1. Reaction pathway between anhydride structure with primary amines.

Functionalization of $P[S-\text { alt }-M A]_{n} \underline{-P E G}$ to $P[S-\text { alt }-R M A]_{n} \underline{-P E G}$
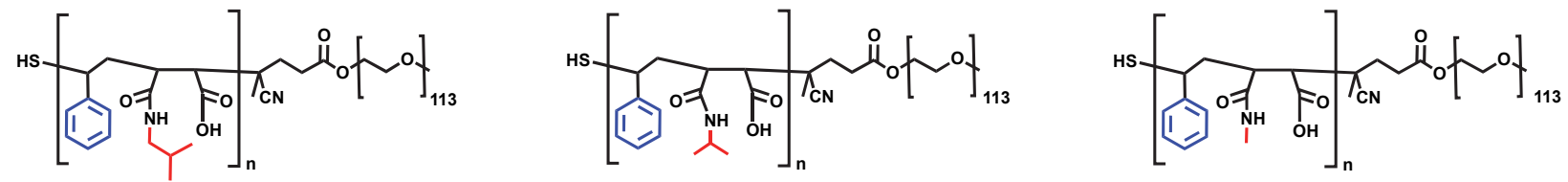

P[S-alt-iBuMA $]_{n}-P E G$ $n=2,4,6$

$$
\text { P[S-alt-iPrMA }]_{n}-\mathrm{PEG}
$$

\section{- For P[S-alt-RMA $]_{2}$-PEG:}

$0.038 \mathrm{~g}\left(0.036 \mathrm{mmol}, 50\right.$ equiv.) of the corresponding amine was dissolved in $1 \mathrm{~mL}$ of $\mathrm{CHCl}_{3}$ and cooled in ice-bath. To this solution was added a solution of $0.062 \mathrm{~g}(0.011 \mathrm{mmol}, 1$ equiv. $)$ of $\mathrm{P}[\mathrm{S}-$ alt-MA]2-PEG that was dissolved in $2 \mathrm{~mL}$ of $\mathrm{CHCl}_{3}$. The reaction mixture was stirred for $10 \mathrm{~min}$. at room temperature and heated subsequently to $70{ }^{\circ} \mathrm{C}$ for $30 \mathrm{~min}$., forcing amide formation and thio-carbonylthio aminolysis to completion. The crude was precipitated 10 times* in diethyl ether and dissolved in $\mathrm{CH}_{2} \mathrm{Cl}_{2}$. The product was obtained as pink powder.

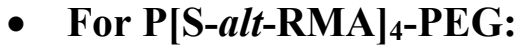

$0.029 \mathrm{~g}$ ( $0.024 \mathrm{mmol}, 50$ equiv.) of the corresponding amine was dissolved in $1 \mathrm{~mL}$ of $\mathrm{CHCl}_{3}$ and cooled in ice-bath. To this solution was added a solution of $0.057 \mathrm{~g}(0.009 \mathrm{mmol}, 1$ equiv. $)$ of P[Salt-MA]4-PEG that was dissolved in $2 \mathrm{~mL}$ of $\mathrm{CHCl}_{3}$. The reaction mixture was stirred for $10 \mathrm{~min}$. at room temperature and heated subsequently to $70{ }^{\circ} \mathrm{C}$ for $30 \mathrm{~min}$. where amide formation and thio-carbonylthio aminolysis was forced to completion. The crude was precipitated 10 times* in diethyl ether and dissolved in $\mathrm{CH}_{2} \mathrm{Cl}_{2}$. The product was obtained as pink powder.

* Commonly the purification of the polymer products by 3-4 times precipitation was sufficient, but careful removal of the excess amines required more cycles. 


\section{- For P[S-alt-RMA $]_{6}$-PEG:}

$0.023 \mathrm{~g}\left(0.040 \mathrm{mmol}, 50\right.$ equiv.) of the corresponding amine was dissolved in $1 \mathrm{~mL} \mathrm{of} \mathrm{CHCl}_{3}$ and cooled in ice-bath. To this solution was added a solution of $0.054 \mathrm{~g}(0.008 \mathrm{mmol}, 1$ equiv. $)$ of P[Salt-MA] 6 -PEG that was dissolved in $2 \mathrm{~mL}$ of $\mathrm{CHCl}_{3}$. The reaction mixture was stirred for $10 \mathrm{~min}$. at room temperature and heated subsequently to $70{ }^{\circ} \mathrm{C}$ for $30 \mathrm{~min}$. where amide formation and thio-carbonylthio aminolysis was forced to completion. The crude was precipitated 10 times* in diethyl ether and dissolved in $\mathrm{CH}_{2} \mathrm{Cl}_{2}$. The product was obtained as pink powder.
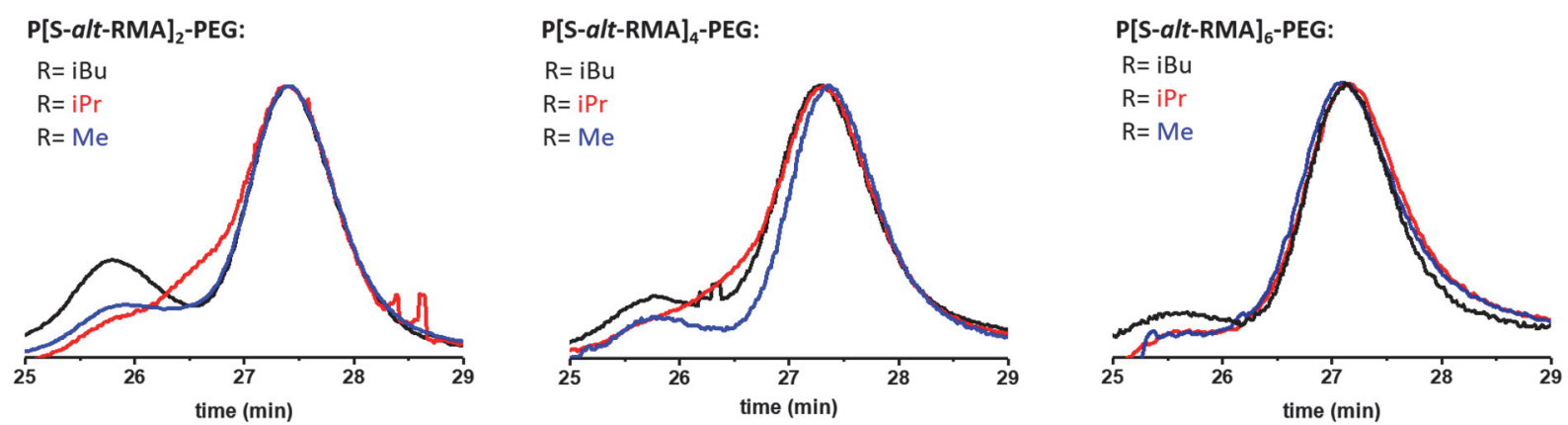

\begin{tabular}{c|c|c|c}
\hline \multicolumn{4}{c}{ P[S-alt-RMA $]_{2}$-PEG } \\
\hline R & Mn & D & DP \\
\hline $\mathrm{iBu}$ & 5872 & 1.03 & 2 \\
\hline $\mathrm{iPr}$ & 5667 & 1.03 & 2 \\
\hline $\mathrm{Me}$ & 5610 & 1.02 & 2 \\
\hline
\end{tabular}

\begin{tabular}{c|c|c|c}
\hline \multicolumn{4}{c}{ P[S-alt-RMA $]_{4}$-PEG } \\
\hline R & Mn & Đ & DP \\
\hline $\mathrm{iBu}$ & 6178 & 1.07 & 4 \\
\hline $\mathrm{iPr}$ & 6170 & 1.08 & 4 \\
\hline $\mathrm{Me}$ & 6076 & 1.07 & 4 \\
\hline
\end{tabular}

\begin{tabular}{c|c|c|c}
\hline \multicolumn{4}{c}{ P[S-alt-RMA] $]_{6}$-PEG } \\
\hline R & Mn & Đ & DP \\
\hline $\mathrm{iBu}$ & 6934 & 1.06 & 6 \\
\hline $\mathrm{iPr}$ & 6785 & 1.07 & 6 \\
\hline $\mathrm{Me}$ & 6637 & 1.05 & 6 \\
\hline
\end{tabular}

Figure S6. GPC data of P[S-alt-RMA $]_{\mathrm{n}}$-PEG after aminolysis.

* Commonly the purification of the polymer products by 3-4 times precipitation was sufficient, but careful removal of the excess amines required more cycles. 

anhydride):P[VBP-alt-MA] $]_{2}-P E G$
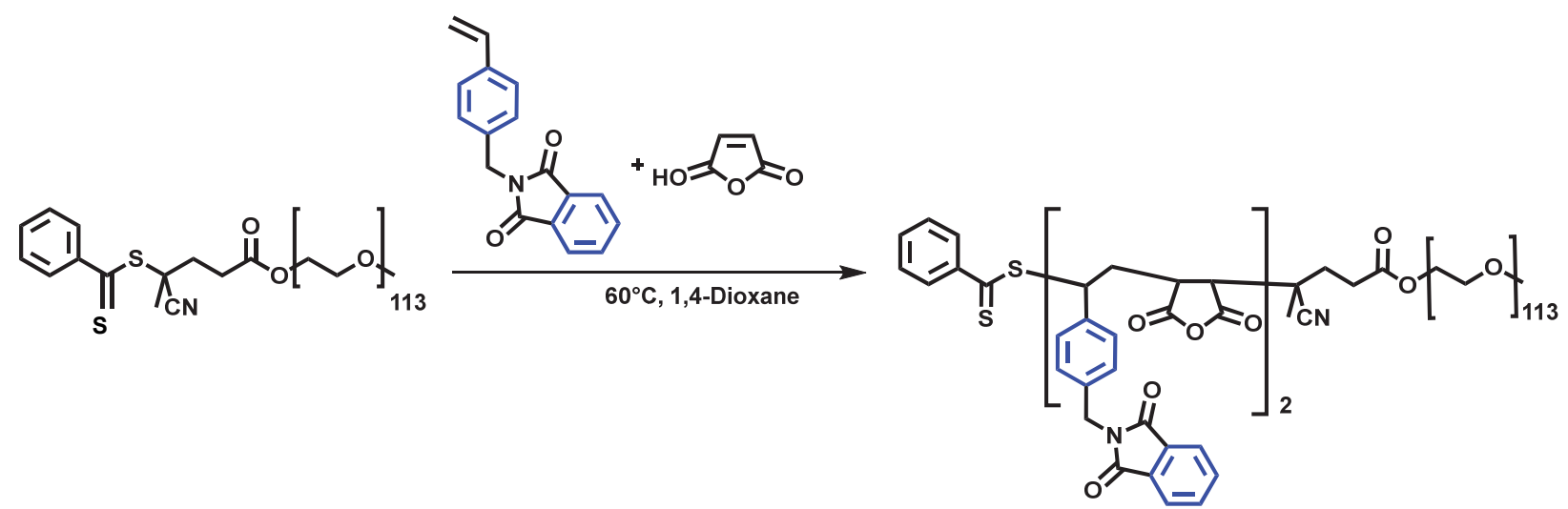

\section{P[VBP-alt-MA $]_{2}$-PEG}

$0.447 \mathrm{~g}$ (4.56 mmol, 20 equiv.) maleic anhydride, $1.2 \mathrm{~g}$ (4.56 mmol, 20 equiv.) $p$-vinyl benzyl phthalimide, $0.0037 \mathrm{~g}$ (0.0228 mmol, 0.1 equiv. $)$ AIBN and $1.2 \mathrm{~g}(0.228 \mathrm{mmol}, 1$ equiv.) RAFTPEO (5000 g/mol) was dissolved in $14 \mathrm{~mL} \mathrm{1,4-dioxane.} \mathrm{After} \mathrm{freeze-pump-thaw} \mathrm{degassing} \mathrm{of} \mathrm{the}$ reaction mixture $(3 \mathrm{x})$ the reaction mixture was heated at $60^{\circ} \mathrm{C}$ for $15 \mathrm{~h}(\mathrm{P}[\mathrm{VBP}-$ alt-MA] $2-\mathrm{PEG}$ $17 \%$ conversion). The polymer was purified by precipitating it in cold diethyl ether and dissolved in dichloromethane $(3 \times)$. 


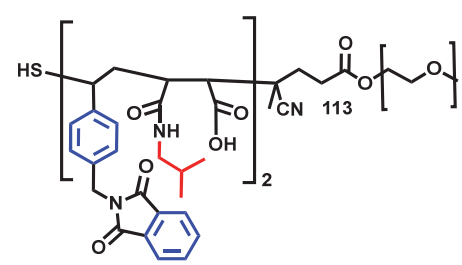

P[VBP-alt-iBuMA]2-PEG

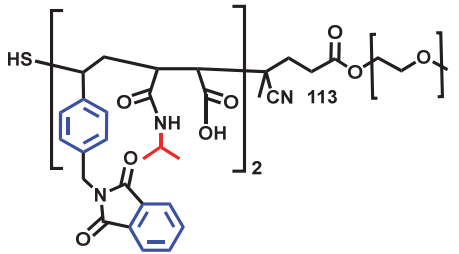

P[VBP-alt-iPrMA $]_{2}-\mathrm{PEG}$

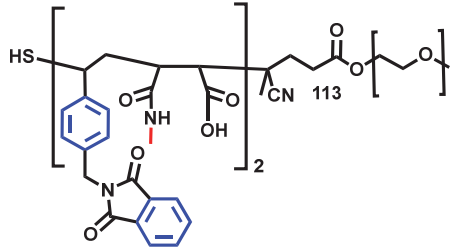

P[VBP-alt-MeMA $]_{2}-\mathrm{PEG}$

\section{- For P[VBP-alt-RMA $]_{2}$-PEG}

$0.026 \mathrm{~g}$ ( $0.036 \mathrm{mmol}, 50$ equiv.) of the corresponding amine was dissolved in $1 \mathrm{~mL}$ of $\mathrm{CHCl}_{3}$ and cooled in ice-bath. To this solution was added a solution of $0.048 \mathrm{~g}(0.007 \mathrm{mmol}, 1$ equiv. $)$ of $\mathrm{P}[\mathrm{VBP}-\text { alt-MA }]_{2}-\mathrm{PEG}$ that was dissolved in $2 \mathrm{~mL}$ of $\mathrm{CHCl}_{3}$. The reaction mixture was stirred for $10 \mathrm{~min}$. at room temperature and heated subsequently to $70{ }^{\circ} \mathrm{C}$ for $30 \mathrm{~min}$. where amide formation and thio-carbonylthio aminolysis was forced to completion. The crude was precipitated 10 times* in diethyl ether and dissolved in $\mathrm{CH}_{2} \mathrm{Cl}_{2}$. The product was obtained as pink powder.

\begin{tabular}{c|c|c|l} 
Polymer & Mn & Đ & DP* \\
\hline P[VBP-alt-MA] $]_{2}-\mathrm{PEG}$ & 6200 & 1.03 & 2 \\
\hline $\mathrm{P}[\mathrm{VBP}-\text { alt }-\mathrm{BBuA}]_{2}-\mathrm{PEG}$ & 6438 & 1.08 & 2 \\
\hline $\mathrm{P}[\mathrm{VBP}-\text { alt }-\mathrm{PPMA}]_{2}-\mathrm{PEG}$ & 6221 & 1.02 & 2 \\
\hline $\mathrm{P}[\mathrm{VBP}-\text { alt }-\mathrm{MeMA}]_{2}-\mathrm{PEG}$ & 6195 & 1.03 & 2
\end{tabular}

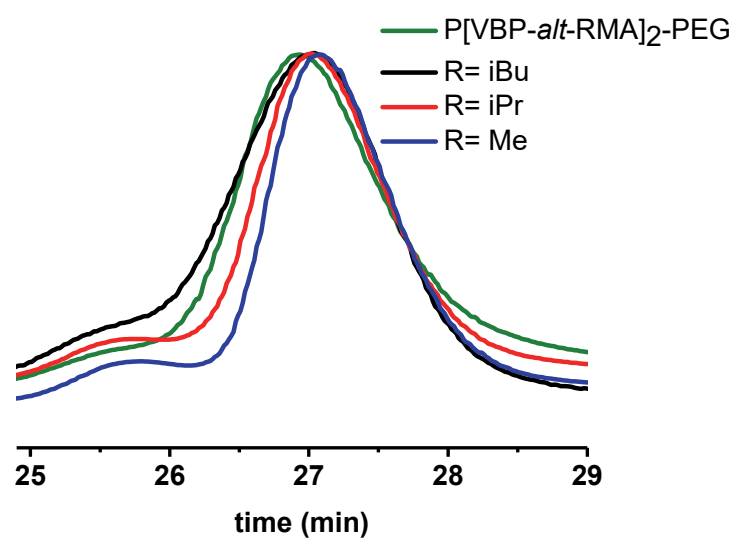

Figure S7. GPC data of P[VBP-alt-MA $]_{2}-\mathrm{PEG}$.

* Commonly the purification of the polymer products by 3-4 times precipitation was sufficient, but careful removal of the excess amines required more cycles. 


\section{Characterization}

\subsection{Infrared spectroscopy (IR)}

\subsection{1. $P[S \text {-alt-RMA] }]_{n-P E G}$}

- a) P[S-alt-RMA $]_{2}-\mathrm{PEG}$

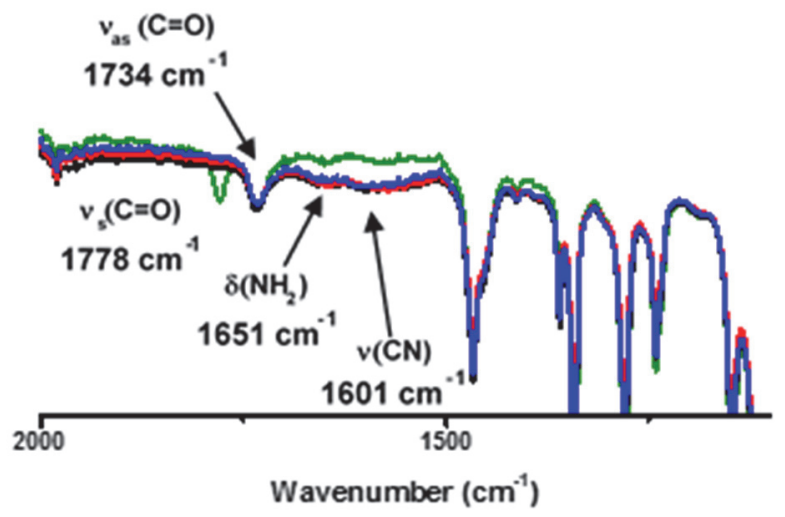

\begin{tabular}{|c|c|c|c|c|c|}
\hline Polymer & $v_{\mathbf{s}}(\mathbf{C O})_{\mathbf{M A}}$ & $v_{\text {as }}(\mathbf{C O})_{\mathbf{M A}}$ & $\boldsymbol{v}(\mathbf{C O})$ & $\boldsymbol{v}\left(\mathbf{N H}_{2}\right)$ & $\boldsymbol{v}(\mathbf{C N})$ \\
\hline $\mathrm{P}[\mathrm{S}-\text { alt }-\mathrm{MA}]_{2}-\mathrm{PEG}$ & $\mathrm{N} . \mathrm{O}$ & 1778 & 1734 & - & - \\
\hline $\mathrm{P}[\mathrm{S}-\text { alt }-\mathrm{BBuMA}]_{2}-\mathrm{PEG}$ & - & - & 1734 & 1651 & 1601 \\
\hline $\mathrm{P}[\mathrm{S}-\text { alt }-\mathrm{P} \mathrm{PrMA}]_{2}-\mathrm{PEG}$ & - & - & 1734 & 1651 & 1601 \\
\hline $\mathrm{P}[\mathrm{S}-\text { alt }-\mathrm{MeMA}]_{2}-\mathrm{PEG}$ & - & - & 1734 & 1651 & 1601 \\
\hline
\end{tabular}


- b) $\mathrm{P}[\mathrm{S}-$ alt-RMA]4-PEG

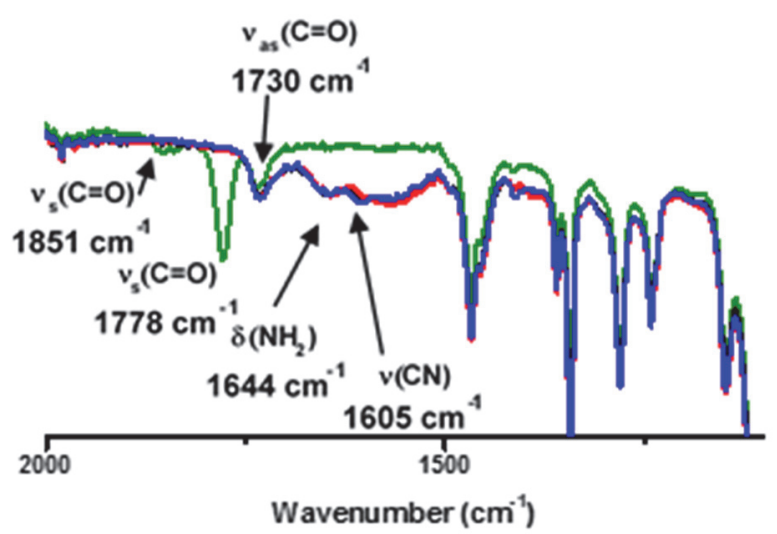

\begin{tabular}{|c|c|c|c|c|c|}
\hline Polymer & $v_{\mathbf{s}}(\mathbf{C O})_{\mathbf{M A}}$ & $v_{\text {as }}(\mathbf{C O})_{\mathbf{M A}}$ & $\boldsymbol{v}(\mathbf{C O})$ & $\boldsymbol{v}\left(\mathbf{N H}_{2}\right)$ & $\boldsymbol{v}(\mathbf{C N})$ \\
\hline $\mathrm{P}[\mathrm{S}-\text { alt }-\mathrm{MA}]_{4}-\mathrm{PEG}$ & 1851 & 1778 & 1730 & - & - \\
\hline $\mathrm{P}[\mathrm{S}-\text { alt } \text { - } \mathrm{BBuMA}]_{4}-\mathrm{PEG}$ & - & - & 1730 & 1644 & 1605 \\
\hline $\mathrm{P}[\mathrm{S}-\text { alt }- \text { iPrMA }]_{4}-\mathrm{PEG}$ & - & - & 1730 & 1644 & 1605 \\
\hline $\mathrm{P}[\mathrm{S}-\text { alt }-\mathrm{MeMA}]_{4}-\mathrm{PEG}$ & - & - & 1730 & 1644 & 1605 \\
\hline
\end{tabular}

c) $\mathrm{P}[\mathrm{S} \text {-alt-RMA }]_{6}-\mathrm{PEG}$

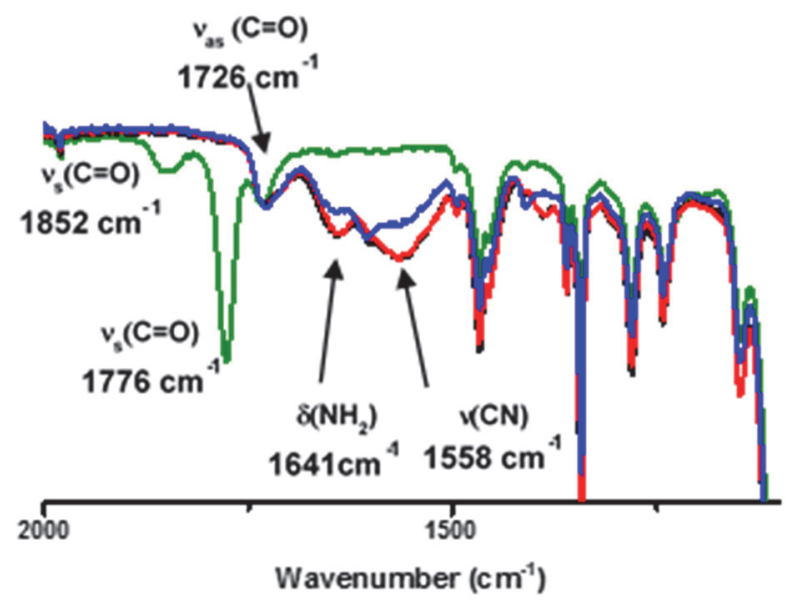

\begin{tabular}{|c|c|c|c|c|c|}
\hline Polymer & $v_{\mathbf{s}}(\mathbf{C O})_{\text {MA }}$ & $v_{\text {as }}(\mathbf{C O})_{\mathbf{M A}}$ & $\boldsymbol{v}(\mathbf{C O})$ & $\boldsymbol{v}\left(\mathbf{N H}_{2}\right)$ & $\boldsymbol{v}(\mathbf{C N})$ \\
\hline $\mathrm{P}[\mathrm{S}-\text { alt }-\mathrm{MA}]_{6}-\mathrm{PEG}$ & 1852 & 1776 & 1726 & - & - \\
\hline $\mathrm{P}[\mathrm{S}-\text { alt } \text {-BuMA }]_{6}-\mathrm{PEG}$ & - & - & 1726 & 1641 & 1558 \\
\hline $\mathrm{P}[\mathrm{S}-\text { alt } \text { - } \mathrm{PrMA}]_{6}-\mathrm{PEG}$ & - & - & 1726 & 1641 & 1558 \\
\hline $\mathrm{P}[\mathrm{S}-\text { alt } \text {-MeMA }]_{6}-\mathrm{PEG}$ & - & - & 1726 & 1641 & 1558 \\
\hline
\end{tabular}


- a) P[VBP-alt-RMA $]_{2}-\mathrm{PEG}$

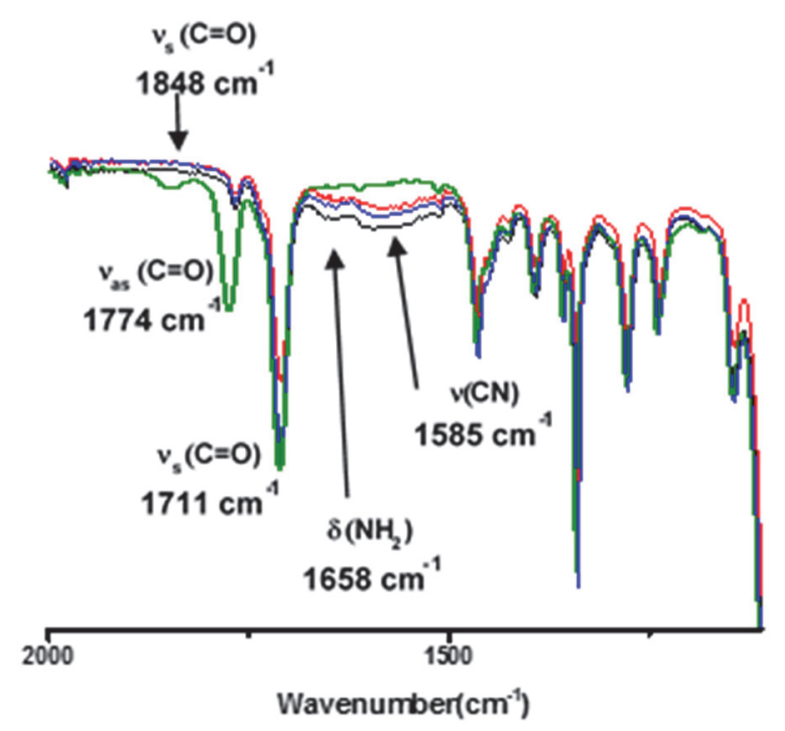

\begin{tabular}{|c|c|c|c|c|c|}
\hline Polymer & $\boldsymbol{v}_{\mathbf{s}}(\mathbf{C O})_{\mathbf{M A}}$ & $\boldsymbol{v}_{\text {as }}(\mathbf{C O})_{\mathbf{M A}}$ & $\boldsymbol{v}(\mathbf{C O})$ & $\boldsymbol{v}\left(\mathbf{N H}_{2}\right)$ & $\boldsymbol{v}(\mathbf{C N})$ \\
\hline $\mathrm{P}[\mathrm{VBP}-\text { alt }-\mathrm{MA}]_{2}-\mathrm{PEG}$ & 1848 & 1774 & 1711 & - & - \\
\hline $\mathrm{P}[\mathrm{VBP}-\text { alt }-\mathrm{BBuMA}]_{2}-\mathrm{PEG}$ & - & - & 1711 & 1658 & 1585 \\
\hline $\mathrm{P}[\mathrm{VBP}-\text { alt }-\mathrm{PPrMA}]_{2}-\mathrm{PEG}$ & - & - & 1711 & 1658 & 1585 \\
\hline $\mathrm{P}[\mathrm{VBP}-\text { alt }-\mathrm{MeMA}]_{2}-\mathrm{PEG}$ & - & - & 1711 & 1658 & 1585 \\
\hline
\end{tabular}


- a) $\mathrm{P}[\mathrm{S}-$ alt-MA]n-PEG

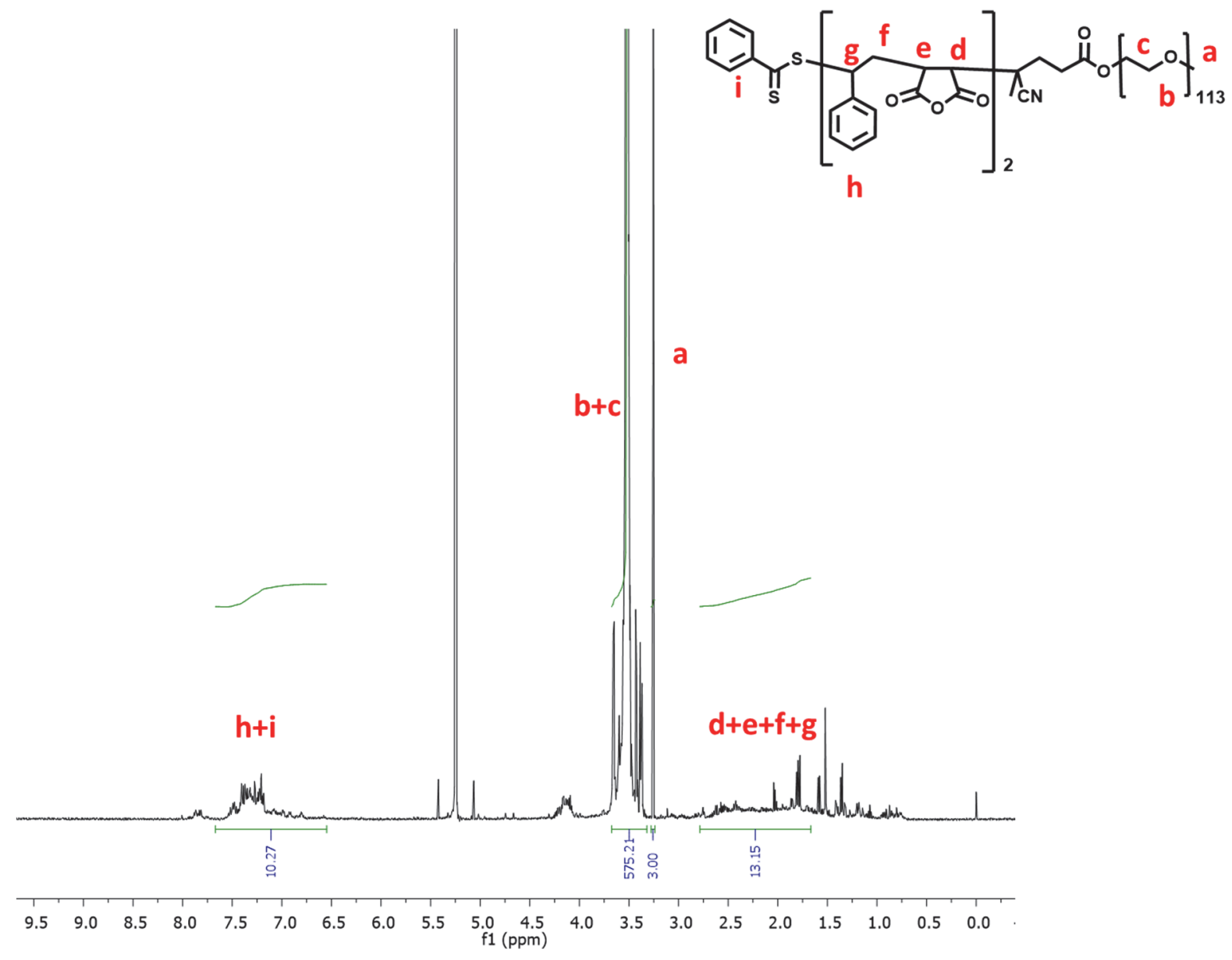

Figure S8. ${ }^{1} \mathrm{H}$ NMR spectra of the polymer $\mathrm{P}[\mathrm{S}-\text { alt-MA }]_{2}-\mathrm{PEG}$ 


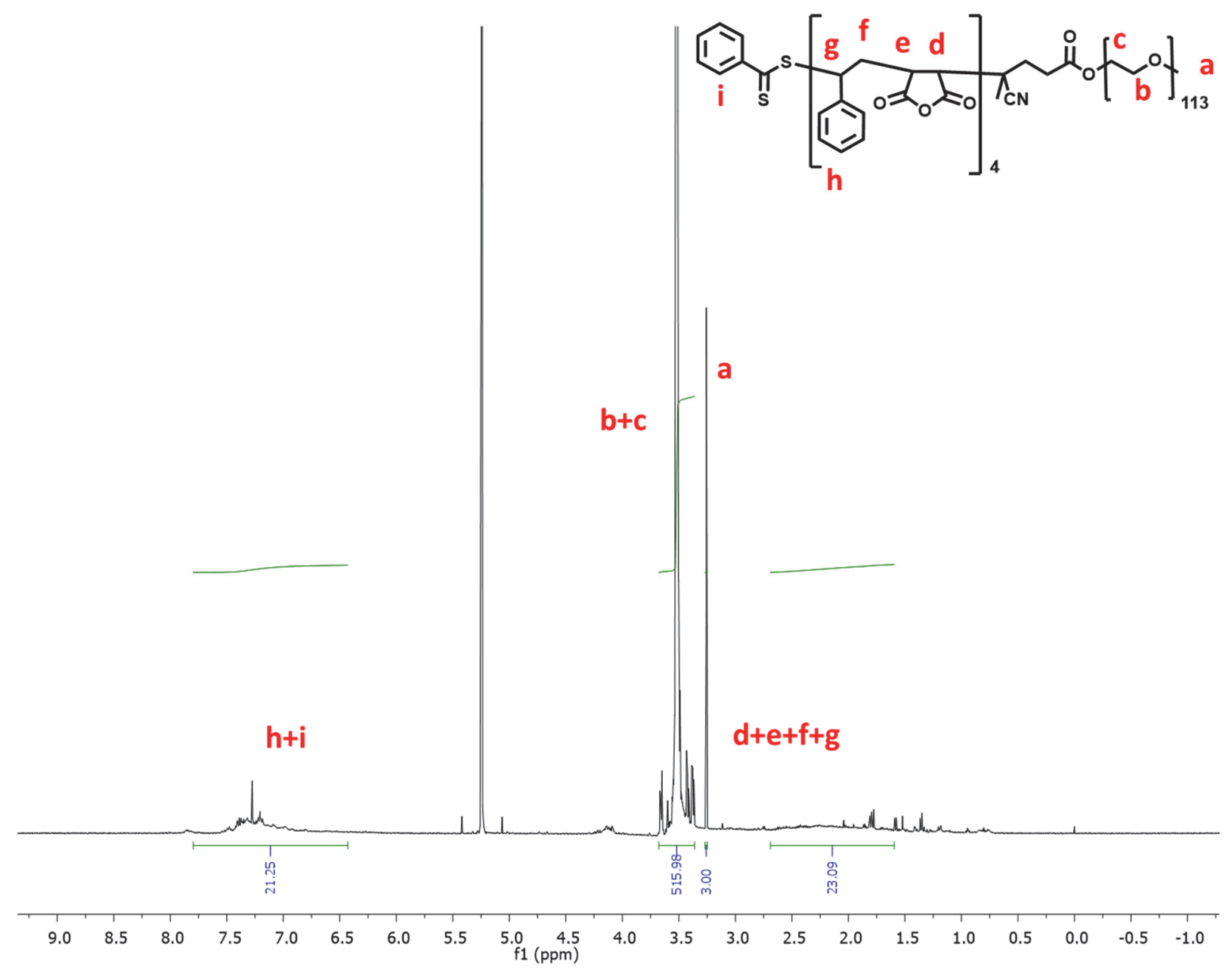

Figure S9. ${ }^{1} \mathrm{H}$ NMR spectra of the polymer P[S-alt-MA $]_{4}-\mathrm{PEG}$ 


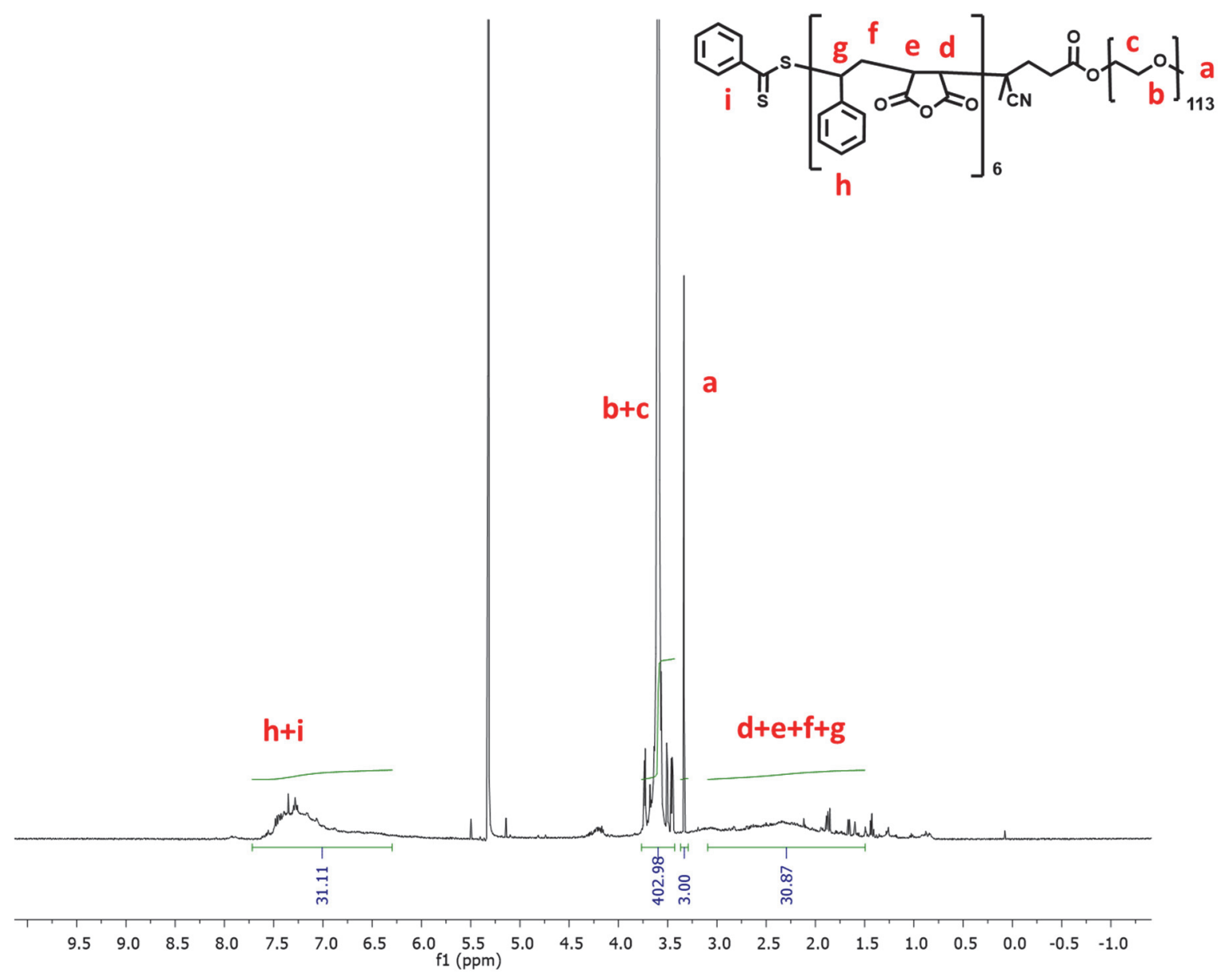

Figure S10. ${ }^{1} \mathrm{H}$ NMR spectra of the polymer $\mathrm{P}[\mathrm{S}-\text { alt-MA }]_{6}-\mathrm{PEG}$. 
- a.1) P[S-alt-RMA $]_{n}-\mathrm{PEG}$

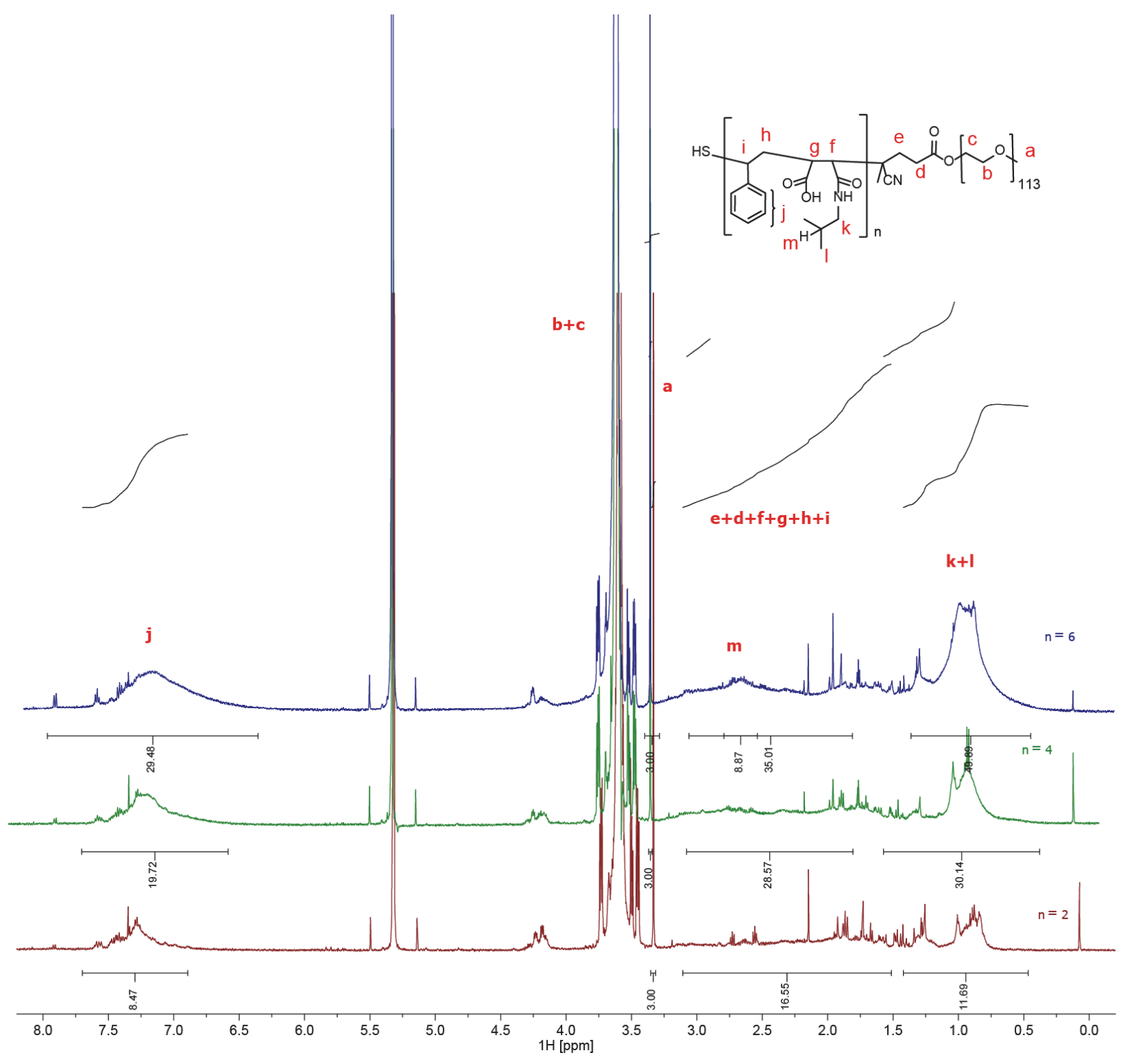

Figure S11. ${ }^{1} \mathrm{H}$ NMR spectra of the polymers $\mathrm{P}[\mathrm{S}-\text { alt-iBuMA }]_{\mathrm{n}}-\mathrm{PEG}, \mathrm{n}=2,4,6$. 


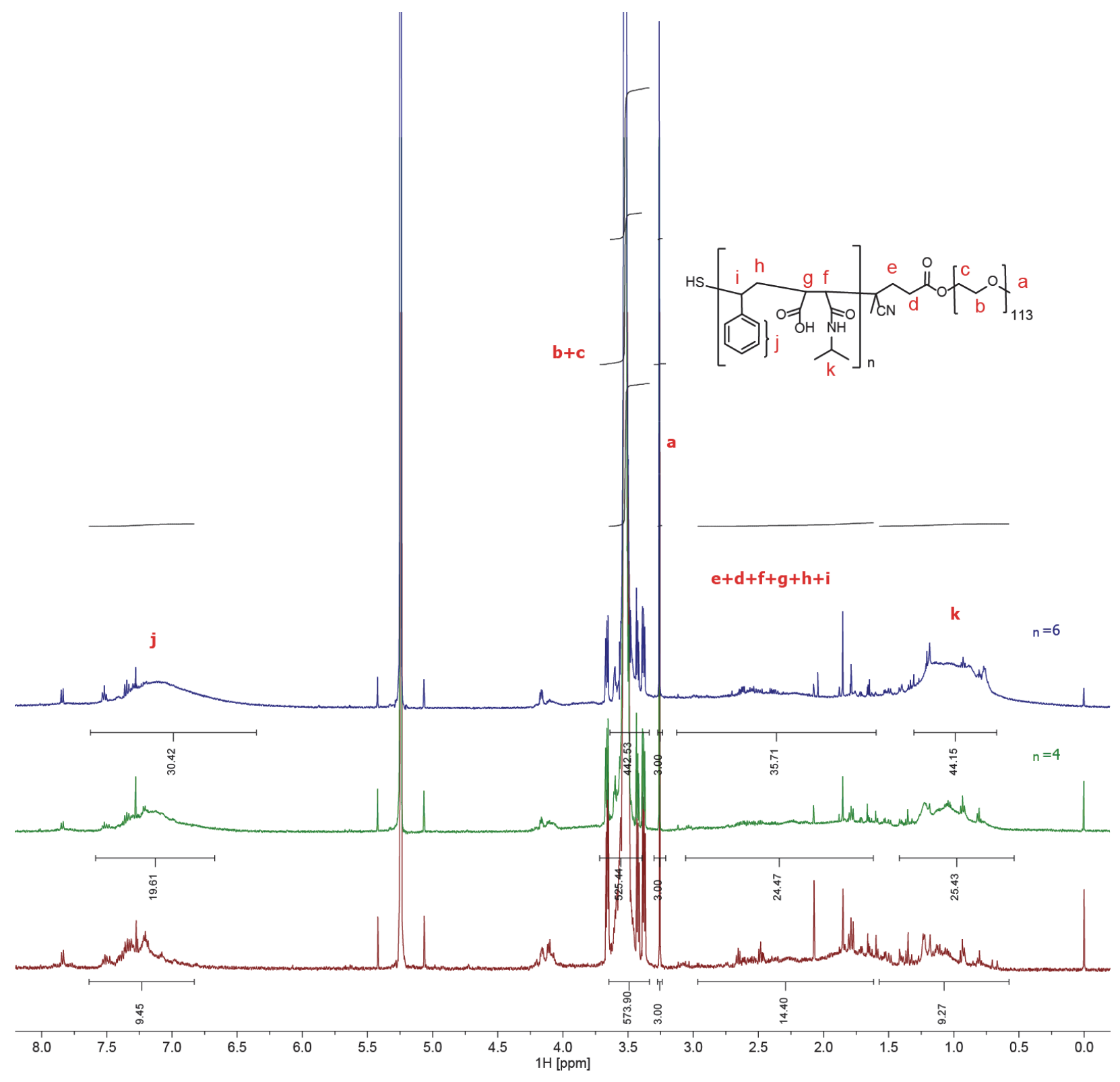

Figure S12. ${ }^{1} \mathrm{H}$ NMR spectra of the polymers $\mathrm{P}[\mathrm{S}-\text { alt }-\mathrm{iPrMA}]_{\mathrm{n}}-\mathrm{PEG}, \mathrm{n}=2,4,6$. 


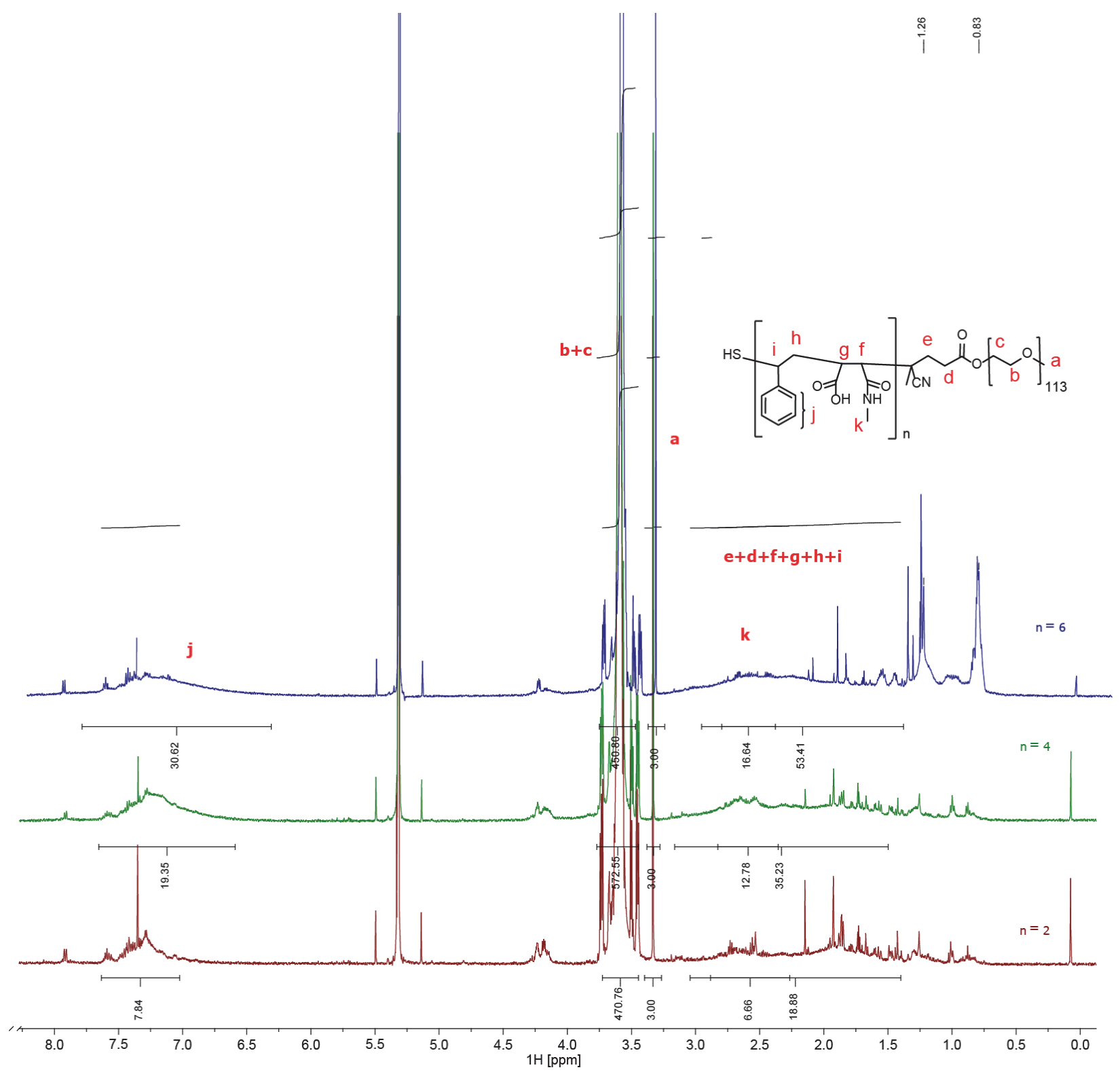

Figure S13. ${ }^{1} \mathrm{H}$ NMR spectra of the polymers $\mathrm{P}[\mathrm{S}-\text { alt }-\mathrm{MeMA}]_{\mathrm{n}}-\mathrm{PEG}, \mathrm{n}=2,4,6$. 
- b) P[VBP-alt-MA $]_{2}-\mathrm{PEG}$

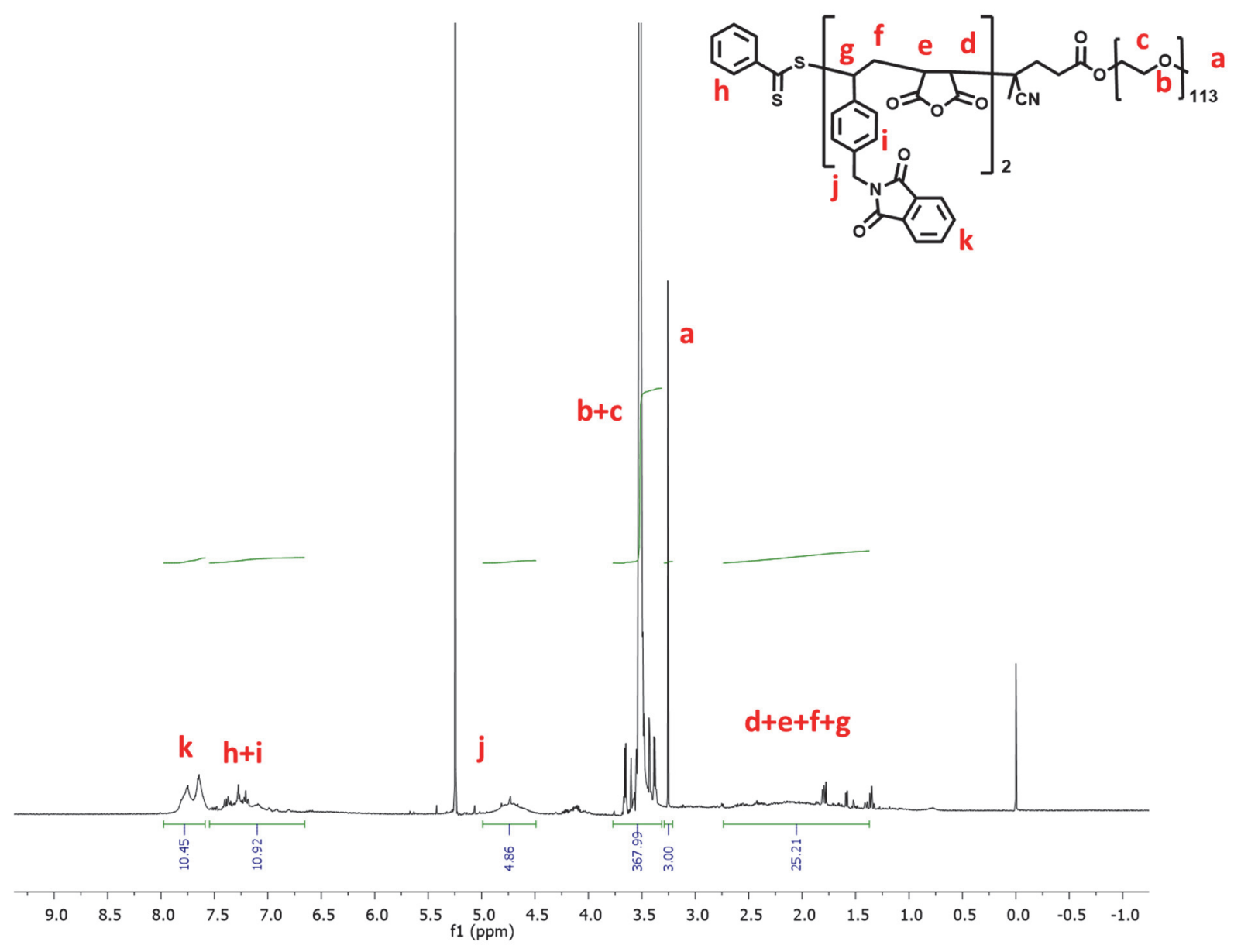

Figure S14. ${ }^{1} \mathrm{H}$ NMR of $\mathrm{P}[\mathrm{VBP}-\text { alt-RMA }]_{2}-\mathrm{PEG}$. 
- b.1) $\mathrm{P}[\mathrm{VBP}-\text { alt-RMA }]_{2}-\mathrm{PEG}$

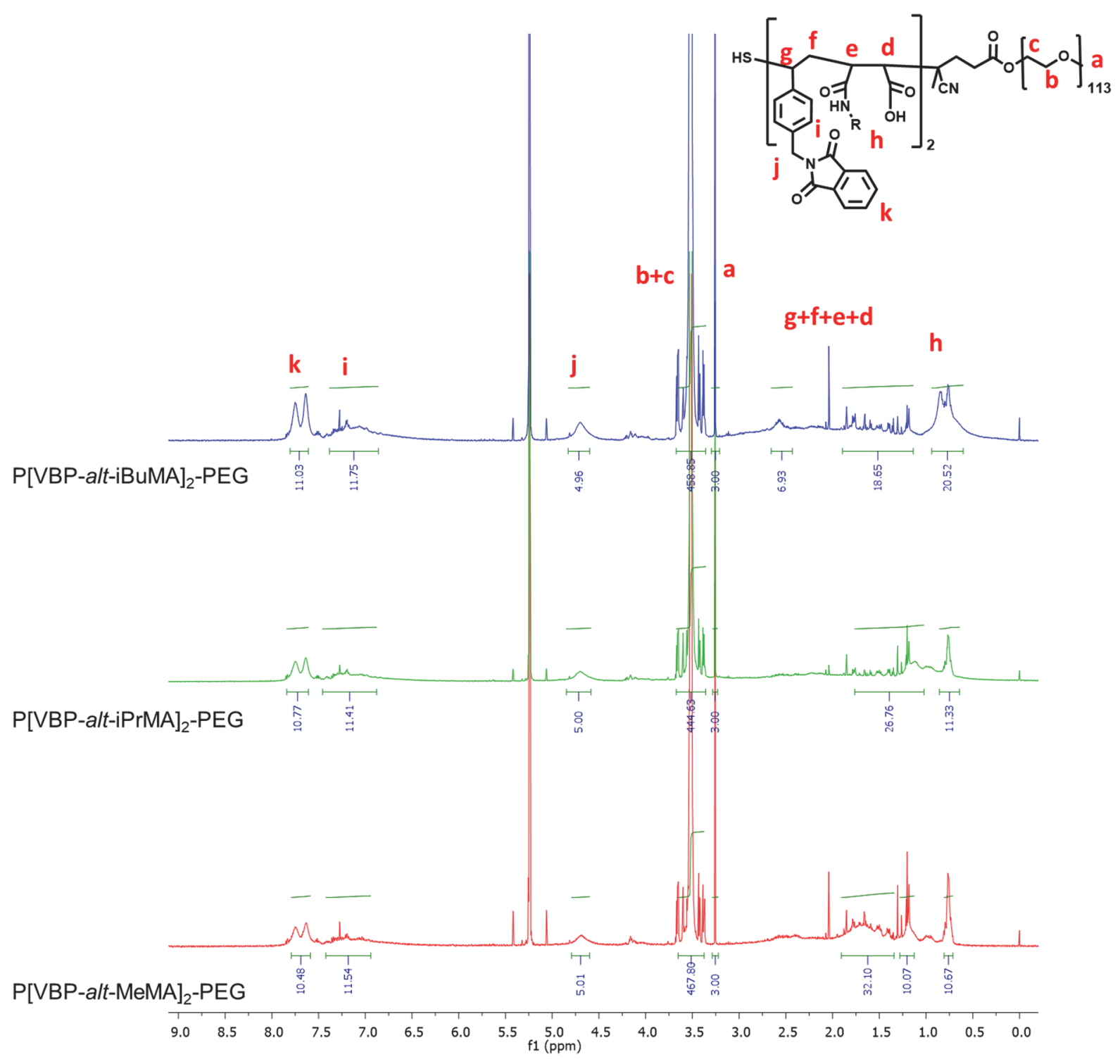

Figure S15. ${ }^{1} \mathrm{H}$ NMR of $\mathrm{P}[\mathrm{VBP}-\text { alt }-\mathrm{RMA}]_{2}$-PEG. 


\section{Solubilization of $m$-THPC}

$m$-THPC was dissolved in $0.5 \mathrm{~mL}$ of EtOH $(1.47 \mu \mathrm{mol} m$-THPC $)$ and added to an aqueous solution of each polymer $(0.5 \mathrm{~mL}$, concentrations are summarized in Table S1). The resulting solutions were shaken at $200 \mathrm{rpm}$ at RT for $1 \mathrm{~h}$, followed by freezing in liquid nitrogen and evaporated in vасио. Residues were dissolved in deionized water $(0.5 \mathrm{~mL})$ and the drug-loaded nanoparticles were separated from non-encapsulated drug by centrifugation (30 min., $13000 \mathrm{rpm}$ ). UV-Vis absorption spectra of each supernatant diluted in ethanol $(1: 99 \mathrm{v} / \mathrm{v})$ were recorded on a Shimadzu UV-2501 PC spectrometer (Shimadzu Corp., 604-8511 Kyoto, Japan). Concentration of m-THPC solubilized by each carrier was calculated through comparison of the absorption maximum at 650 $\mathrm{nm}$ to a calibration curve of the free drug in $\mathrm{EtOH}(0.0001,0.0005,0.001,0.005,0.01 \mathrm{mg} / \mathrm{mL})$. Maximum payload capacity of each carrier is summarized in Table S1. Drug/polymer complexes were analyzed by Dynamic Light Scattering (DLS)(Figures S17-S18).

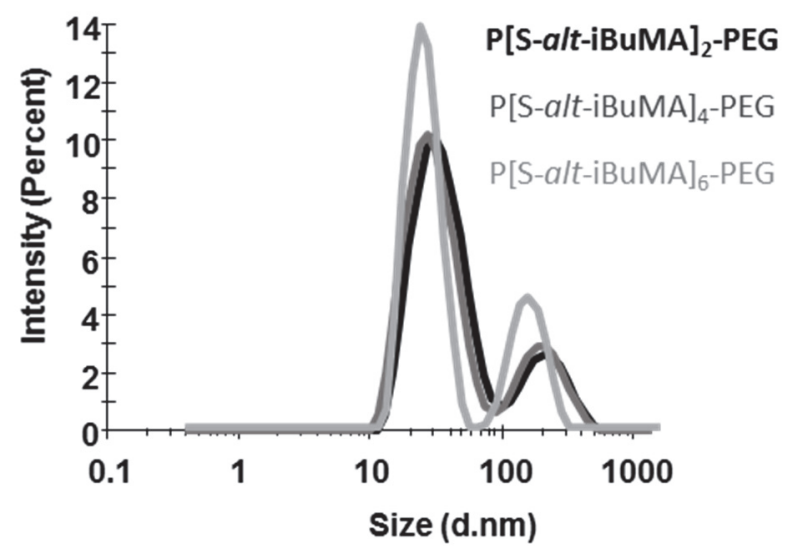

Figure S16. DLS-analyzed of P[S-alt-iBuMA $]_{\mathrm{n}}-\mathrm{PEG}$. 
a)

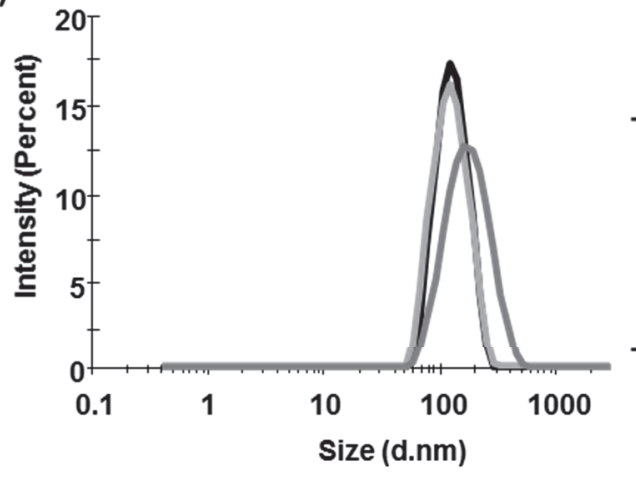

\begin{tabular}{|c|c|c|}
\hline & $\mathbf{R}_{\mathrm{H}}$, DLS $(\mathrm{nm})$ & PDI,DLs \\
\hline Polymer* & & \\
\hline $\mathrm{P}[\mathrm{S} \text {-alt-iBuMA }]_{2}-\mathrm{PEG}+m-\mathrm{THPC}$ & 60 & 0.089 \\
\hline $\mathrm{P}[\mathrm{S} \text {-alt-iBuMA }]_{4}-\mathrm{PEG}+m$-THPC & 79 & 0.128 \\
\hline P[S-alt-iBuMA $]_{6}-\mathrm{PEG}+m$-THPC & 57 & 0.116 \\
\hline
\end{tabular}

b)

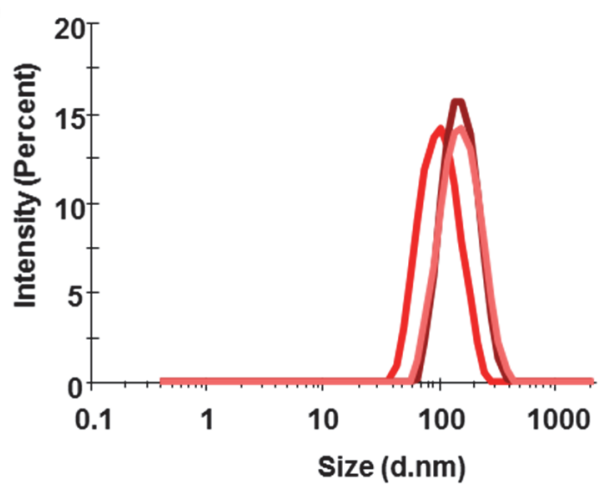

\begin{tabular}{|c|c|c|}
\hline & $\mathbf{R}_{\mathrm{H}, \mathrm{DLS}}(\mathrm{nm})$ & PDI $_{\text {DLS }}$ \\
\hline Polymer* & & \\
\hline P[S-alt-iPrMA $]_{2}-\mathrm{PEG}+m$-THPC & 75 & 0.107 \\
\hline P[S-alt-iPrMA $]_{4}-\mathrm{PEG}+m$-THPC & 55 & 0.090 \\
\hline P[S-alt-iPRMA $]_{6}-\mathrm{PEG}+m$-THPC & 73 & 0.137 \\
\hline
\end{tabular}

*multimodal, sample can not be interpreted

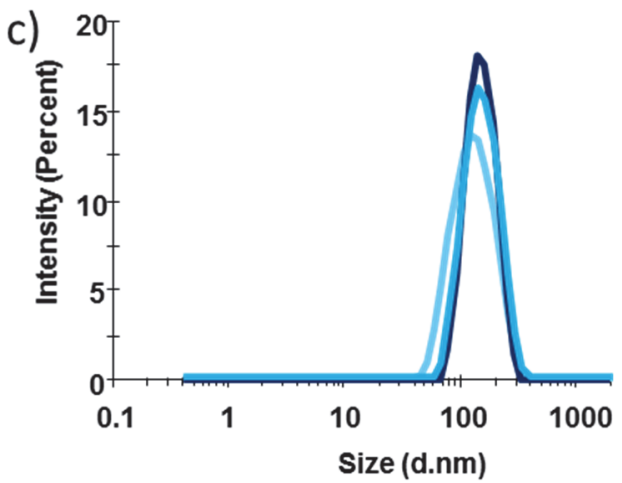

\begin{tabular}{|c|c|c|}
\hline & $\mathbf{R}_{\mathrm{H}}$, DLS $(\mathrm{nm}$ & PDI,DLS \\
\hline Polymer* & & \\
\hline $\mathrm{P}[\mathrm{S} \text {-alt-MeMA }]_{2}-\mathrm{PEG}+m$-THPC & 72 & 0.086 \\
\hline $\mathrm{P}[\mathrm{S}-\text { alt-MeMA }]_{4}-\mathrm{PEG}+m-\mathrm{THPC}$ & 70 & 0.111 \\
\hline P[S-alt-MeMA $]_{6}-\mathrm{PEG}+m$-THPC & 59 & 0.077 \\
\hline
\end{tabular}

*multimodal, sample can not be interpreted

Figure S17. DLS-analyzed hydrodynamic radii and dispersity of $m$-THPC loaded nanoparticles of a) P[Salt-iBuMA $]_{\mathrm{n}}-\mathrm{PEG}$, b) P[S-alt-iPrMA$]_{\mathrm{n}}-\mathrm{PEG}$ and a) P[S-alt-MeMA $]_{\mathrm{n}}-\mathrm{PEG}$. 
- $\mathrm{P}[\mathrm{VBP}-\text { alt-RMA }]_{2}$-PEG

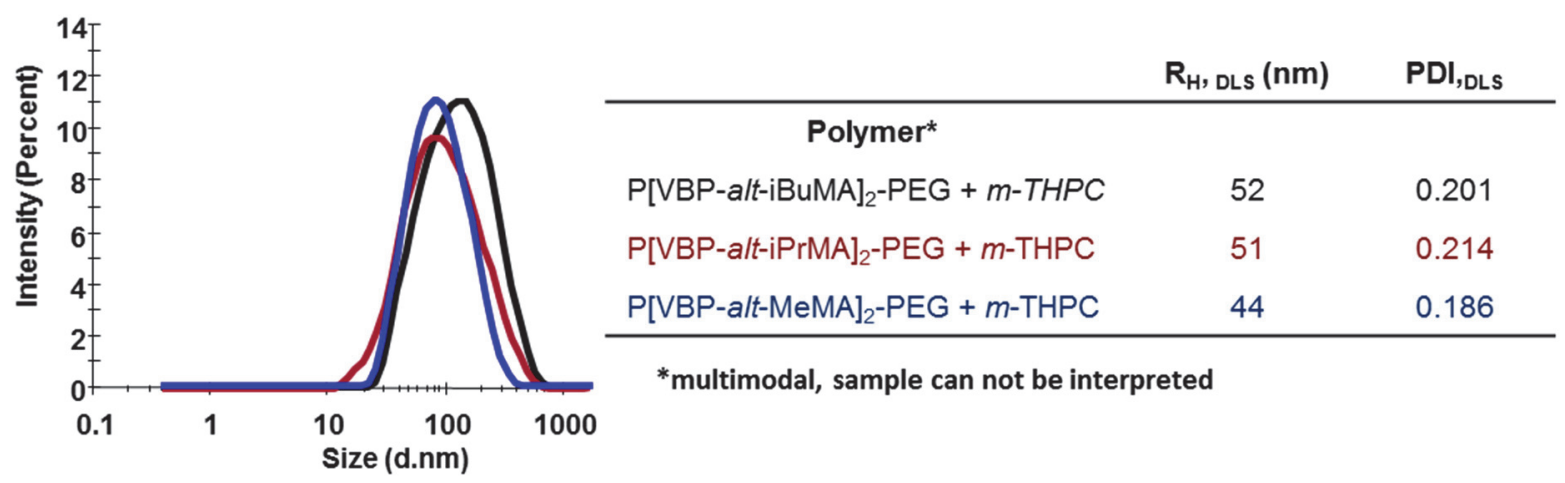

Figure S18. DLS-analyzed hydrodynamic radii and dispersity of $m$-THPC loaded nanoparticles of P[VBPalt-RMA $]_{2}$-PEG. 


\section{Drug release studies}

For fluorescence-measurement, drug-loaded polymer solutions were dissolved in Millipore water to obtain $280 \mu \mathrm{L}$ of $0.1 \mu \mathrm{M} \mathrm{m}$-THPC concentrations that were filled in a 96-well plate. The release was initiated by adding $20 \mu \mathrm{L}$ aqueous BSA-solution $(100 \mu \mathrm{M})$. Additionally, same drug loaded solutions were treated with $20 \mu \mathrm{L}$ aqueous Triton-X solution $(0.1 \%)$ to get a top fluorescence release-experiment. Top-up experiments were normalized to fluorescence measurement of $0.1 \mu \mathrm{M}$ $m$-THPC solutions with $0.1 \%$ Triton-X solution. Samples were exited at $417 \mathrm{~nm}$ and emission was recorded at $654 \mathrm{~nm}$ every $2 \mathrm{~min}$ for $18 \mathrm{~h}$ (gain 80 , slit 20, sample width $8.00 \mathrm{~mm}$ ). For each polymer the release was measured 3 times and the arithmetic mean was calculated to give the fluorescence release curve.

Table S1. Solubilization of $m$-THPC by using standard solubilization experiment with indicated used polymer, molar mass, and resulting end concentrations of polymer solutions and molar ratio of drug to polymer.

\begin{tabular}{|c|c|c|c|c|c|c|c|c|c|c|c|}
\hline \multirow{5}{*}{$\begin{array}{c}\text { polymer } \\
{\left[\begin{array}{c}\text { VBP-alt-RMA }]_{n} \\
\text {-PEG }\end{array}\right.}\end{array}$} & \multirow{2}{*}{\multicolumn{4}{|c|}{$\begin{array}{c}\text { sidechain } \\
\text { functionalities }\end{array}$}} & \multirow{3}{*}{\multicolumn{2}{|c|}{$\begin{array}{l}n \\
2\end{array}$}} & \multirow{3}{*}{$\begin{array}{c}\begin{array}{c}\text { conc. } \\
\text { [mM] } \\
\text { a) }\end{array} \\
0.29\end{array}$} & \multicolumn{3}{|c|}{ Upload with m-THPC } & \multirow{3}{*}{$\begin{array}{c}\begin{array}{c}\text { Initial } \\
\text { release }^{d)}\end{array} \\
11500\end{array}$} \\
\hline & & & & & & & & \multirow{2}{*}{$\frac{\text { b) }}{1: 13.6}$} & \multicolumn{2}{|c|}{$[g]^{c)}$} & \\
\hline & VBP & & $\mathrm{OOH}$ & B & & & & & 0.044 & \pm 0.003 & \\
\hline & VBP & & $\mathrm{\partial OH}$ & P & & 2 & 0.29 & $1: 5.8$ & 0.109 & \pm 0.021 & 11100 \\
\hline & VBP & & $\mathrm{OOH}$ & M & & 2 & 0.29 & $1: 3.4$ & 0.126 & \pm 0.042 & 9800 \\
\hline \multirow{9}{*}{$\begin{array}{c}{[\text { Sty-alt-RMA }]_{n}} \\
\text {-PEG }\end{array}$} & \multirow{3}{*}{ Sty } & \multirow{2}{*}{\multicolumn{2}{|c|}{$\mathrm{COOH}$}} & & & 2 & 1.57 & 1: 23.9 & 0.045 & \pm 0.004 & 40000 \\
\hline & & & & B & & 4 & 1.50 & $1: 3.2$ & 0.157 & \pm 0.015 & 8300 \\
\hline & & & & & & 6 & 1.53 & 1: 1.7 & 0.205 & \pm 0.011 & 6300 \\
\hline & \multirow[b]{2}{*}{ Sty } & \multirow{2}{*}{\multicolumn{2}{|c|}{$\mathrm{COOH}$}} & \multirow{3}{*}{$\operatorname{Pr}$} & & 2 & 1.50 & 1: 19.4 & 0.036 & \pm 0.008 & 25500 \\
\hline & & & & & & 4 & 1.51 & 1: 4.4 & 0.118 & \pm 0.002 & 13500 \\
\hline & & & & & & 6 & 1.52 & $1: 2.5$ & 0.147 & \pm 0.011 & 12300 \\
\hline & \multirow{3}{*}{ Sty } & \multirow{3}{*}{\multicolumn{2}{|c|}{$\mathrm{COOH}$}} & \multirow{3}{*}{$\mathrm{Me}$} & & 2 & 1.52 & 1: 55.5 & 0.020 & \pm 0.008 & 37400 \\
\hline & & & & & & 4 & 1.51 & 1: 18.4 & 0.034 & \pm 0.012 & 12500 \\
\hline & & & & & & 6 & 1.53 & $1: 7.2$ & 0.063 & \pm 0.022 & 14400 \\
\hline Pep-QFFLFFQ & Q & $\mathrm{F}$ & L & $\mathrm{F}$ & & Q & 1.47 & $1: 3.9$ & \multicolumn{2}{|c|}{0.26} & 2200 \\
\hline Pep-QFFVFFQ & $Q$ & $\mathrm{~F}$ & V & $\mathrm{F}$ & & Q & 1.47 & $1: 8.9$ & \multicolumn{2}{|c|}{0.11} & 1000 \\
\hline Pep-QFFAFFQ & Q & $\mathrm{F}$ & A & $\mathrm{F}$ & & Q & 1.47 & 1: 41.1 & \multicolumn{2}{|c|}{0.02} & 2700 \\
\hline
\end{tabular}

a) polymer concentration used in solubilization experiment, b) mol ratio drug:carrier, c) mass of solubilized drug per $\mathrm{g}$ of functional segment $[\mathrm{g}], \mathrm{d})$ determined by 1 st order derivative at $\mathrm{t}=0 \mathrm{~min}$. 

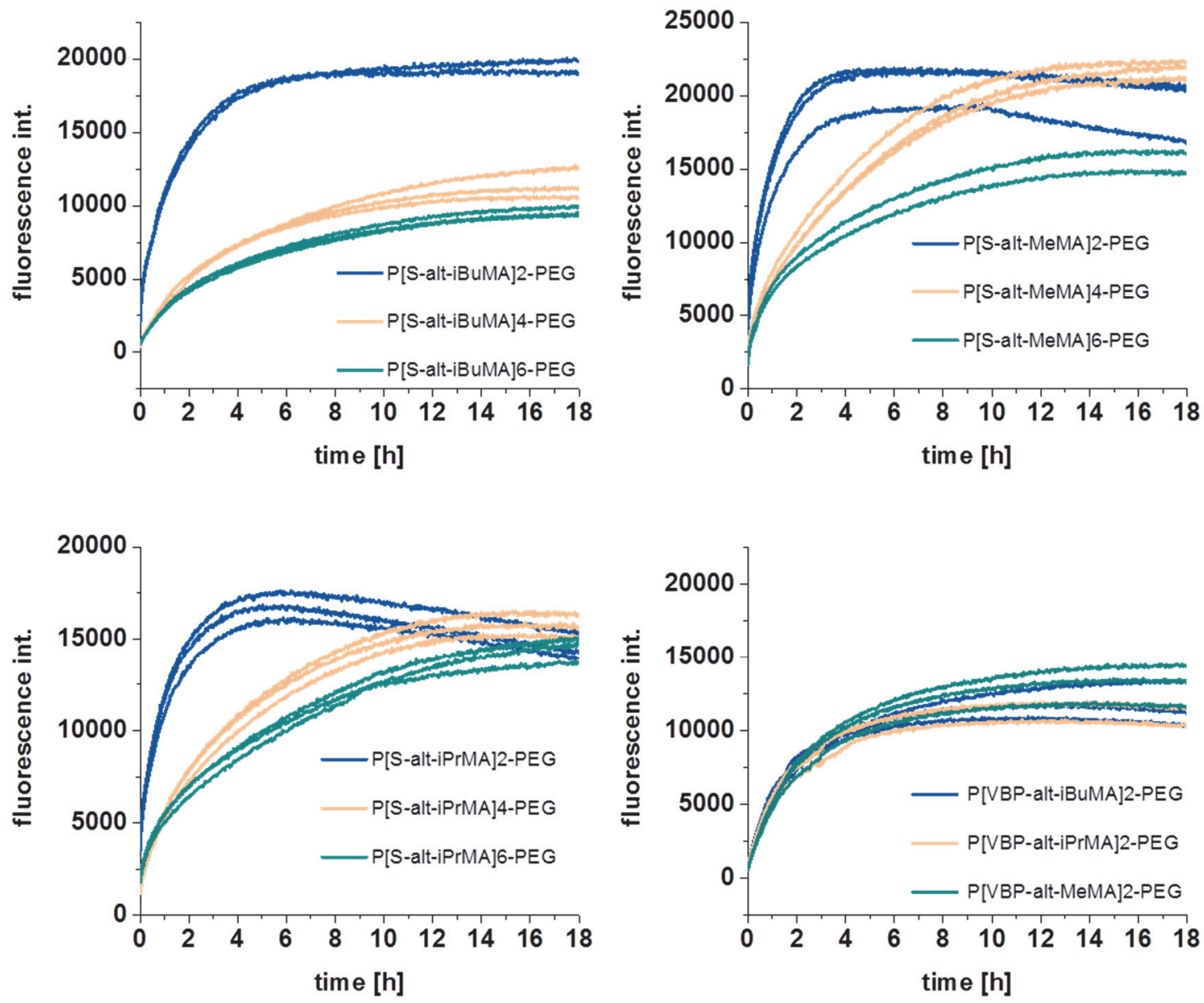

Figure S19. Original data sets of the release kinetics from drug loaded polymer-PEG solubilizers. These curves constitute the arithmetic mean release curves. Repetition experiments are presented in the same color. 